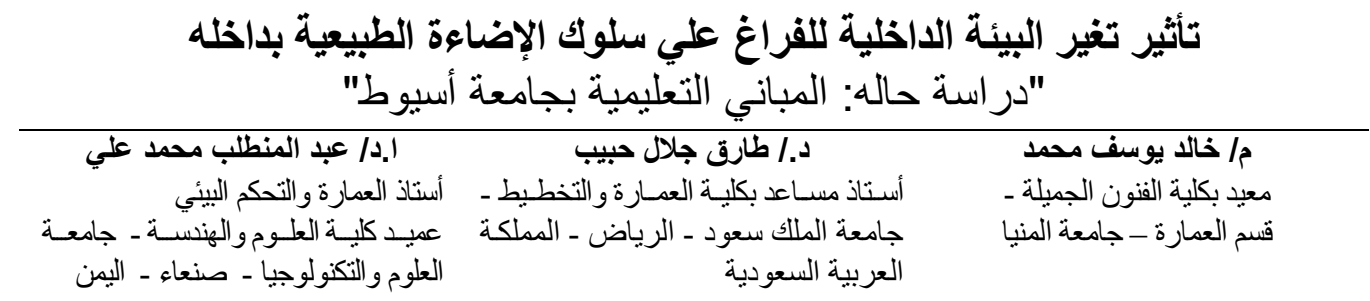

a.monteleb@ust.edu.ya

t.habib@ksu.edu.sa

Arch_khaled2005@yahoo.com

(Received December 17, 2008 Accepted January 13, 2009)

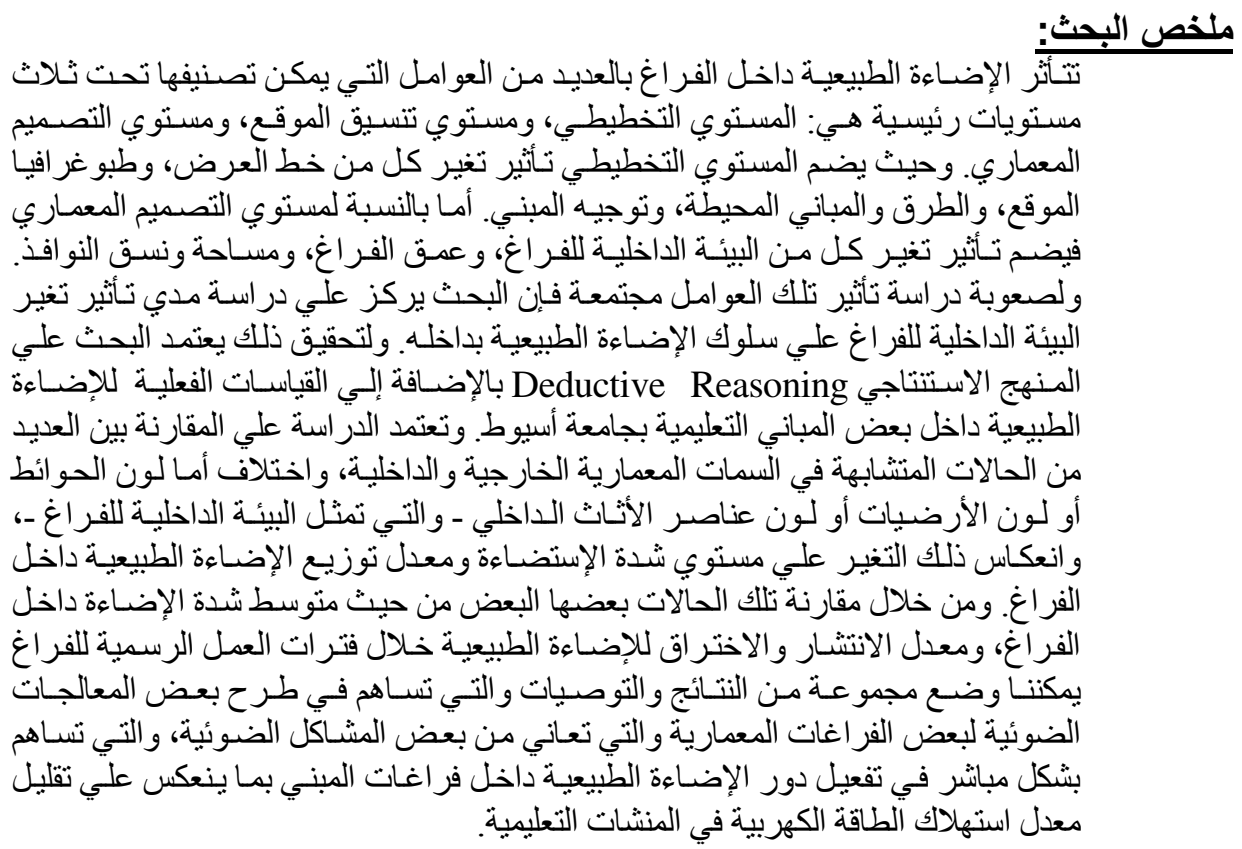

\title{
IMPACT OF SPACE INNER ENVIRONMENT ON THE BEHAVIOR OF DAYLIGHTING CASE STUDY OF EDUCATIONAL BUILDING, ASSIUT UNIVERSITY
}

Natural lighting within a space could be affected by many factors. These factors could be grouped under three levels: planning levels, landscape level and architectural design level, as planning level impact of changing both the latitude and topography of the site, roads and building surrounding the site could also be important factors. On the landscape level many factors could be involved as the materials used in the surrounded spaces, green built. On the other hand, as for the level of architectural design, it incorporates the impact of changing both the interval environment of the spaces and the dimensions of the space itself size and pattern of windows could 
also be a main factor at the process. Because at the difficulty of studying the impact of those factors together. The paper focus on the impact at internal environment of the space on the behavior of natural light inside the space.

To achieve this task. The paper has depended on the deductive reasoning approach in addition to the actual measurements of natural lighting in some educational building of Assiut University. The study is based on the comparison of many similar eases in the architectural features of the external and internal. The only different was the color, color of wall, floors, or furniture, elements represents the internal environment of intensity and the rate of distribution of natural lighting within the spaces.

By comparing these case each of average intensity of natural lighting and proliferation and penetration of natural lighting during official working hours, we can develop a set of finding and recommendations and contributing to select suitable treatments for certain case suffering from natural lighting problems. The paper also contribute directly to activate the role of natural lighting within building spaces, that would reduce the rate of electrical consumption in educational facilities.

تعتمد ساعات التشغيل للفراغات التعليمية علي الفترة النهارية. الأمر الذي يتطلب توفير قدر من الإضـاءة بما

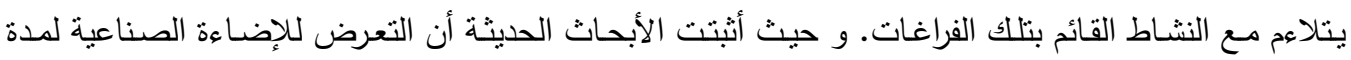
طويلة يتسبب في حدوث أضرار صحية للإنسان على المستويين النفسي والجسدي. حيث تعد عملية التعرض للتذبذبات الضوئية لمصابيح الفلورسنت والافتقاد للإضاءة الطبيعية أهم الآثار السلبية الناجمة عن العمل المكتبي.

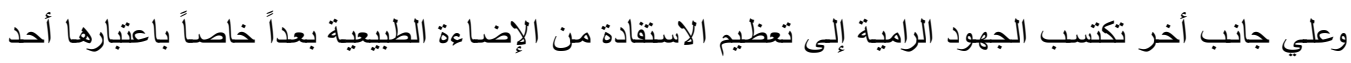

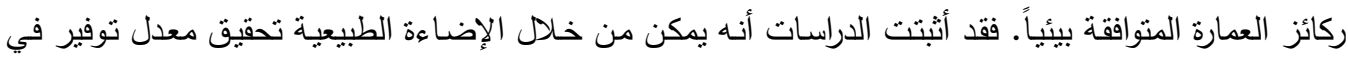
نفقات استهالك الطاقة يتراوح ما بين 30\% - 70\% شرط الاستفادة من أجهزة الإضاءة الصناعية بشكل جيد. إشكالبة الدراسةة: تعد الإضاءة الطبيعية إحدى المقومات المناخية التي تتميز بها مصر ، والتي تعد إحدى الركائز الأساسية لكثير

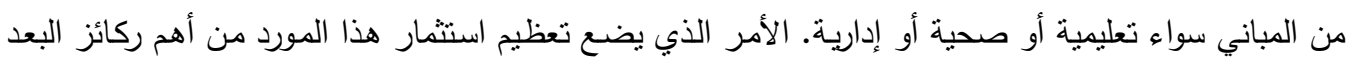
البيئي. وقد تتاولت العديد من الدراسـات الإضـاءة الطبيعية داخل المباني، كما أجرت العديد من الدول الأوربية دراسات ضوئية نتتاول نأثثر تغير البيئة الداخلية، وتم اخذ هذه التجارب ونطبيق نتائجها علي المباني التعليمية في مصر بدون التحقق من ملاءمتها للظروف المناخية الخاصـة بمصر ـ وعليه فإن البحث يتحقق من مدي ملائمة تللك الدراسات مع البيئة المصرية بوجه عام ولمباني جامعة أسيوط بشكل خاص. وعليه فإن للبحث سؤالاً محورياً 
مـا مدي تأثير الوسط البئي الداخلي للقراغ علي سلوك الإضـاءة الطيعيةة؟ وهل يمكن تفعيل دور الإضـاءة الطبعية داخل الفراغ من خلال تغبر البيئة الداخلية للقراغ؟

الإهف من الدراسة:

تهدف الدراسـة إلي فهم وإدراك مدي تأثير الوسط البيئي الداخلي للفراغ علي مستوي شدة الإستضـاءة ومعدل

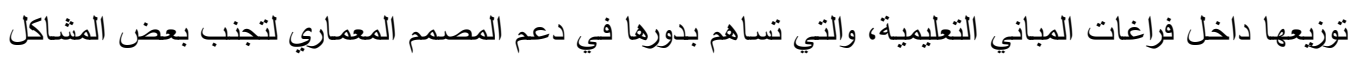

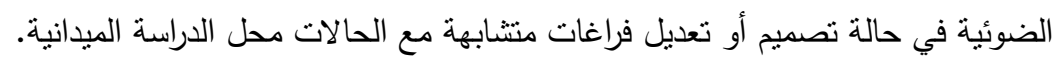

منهِية البحث:

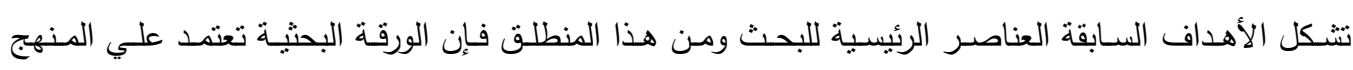

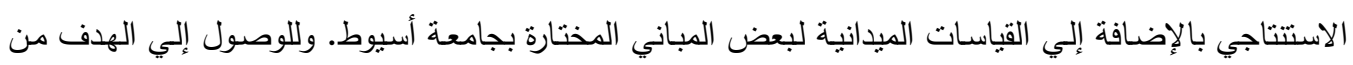
البحث ينبغي دراسة تلك النقاط: - أسباب تفضيل الإضاءة الطبيعية عن الإضاءة الصناعية. 2- - - العوامل المؤثرة علي تحقيق الراحة البصرية.

$$
\text { 3 - - - مركبات الإضاءة الطبيعية. }
$$

4- الخلفية النظرية لتأثير تغير الوسط البيئي الاخاخلي للفراغ علي سلوك الإضاءة الطبيعية. -6 - منهجية الدراسة الميدانية. 6- تحليل القياسات الضوئية للمباني المختارة.

1- أسباب تفضيل الإضاءة الطبيعية عن الإضاءة الصناعية:

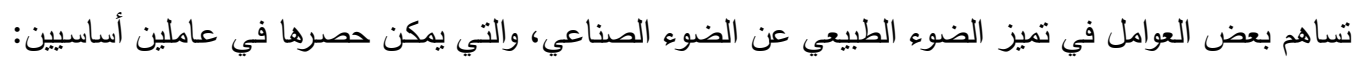

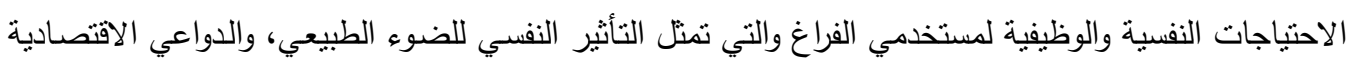
وتتامي الدعوة إلي استخدام الموارد المتجددة للطاقة.

\section{1-1 إنأثير النفسي والوظيفي للإضاءة الطبيعية:}

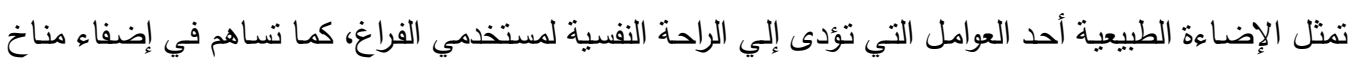

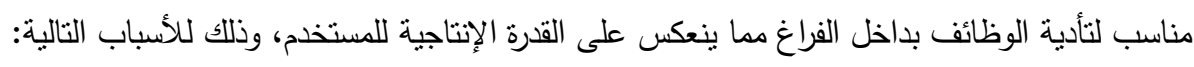

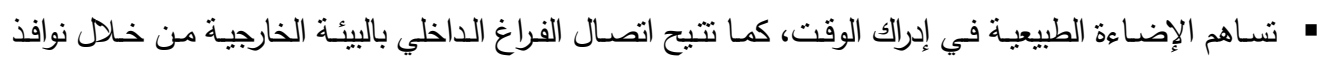
الضوء[1]. يؤدي تغير الإضـاءة الطبيعية على مدار اليوم بشكل تدريجي إلي تغير طبيعة الفراغ الداخلي بمعدل يسهل عمليه النكيف معه[2]]. 
" تعتبر الإضاءة الطييعية - خاصة عند تواجد النوافذ علي الواجهات الثمالية - وسط صحيح لمراجعة الألوان،

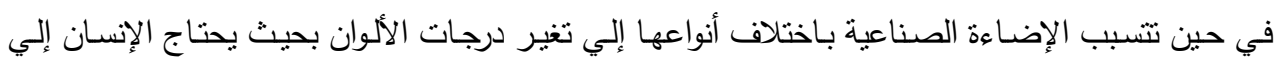
تعريض الأجسام للإضاءة الطبيعية لمعرفة ألوانها الحقيقية[3].

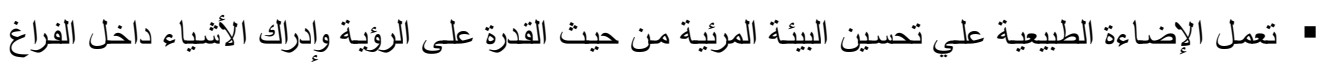
بدقة[4].

\section{2-1 دور الإضاءة الطبيعية في خفض معدلات استهلاك الوقود:}

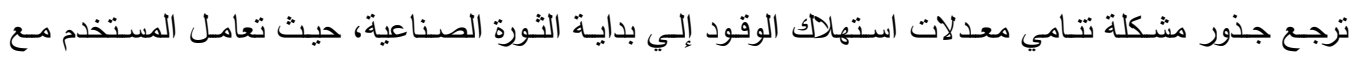

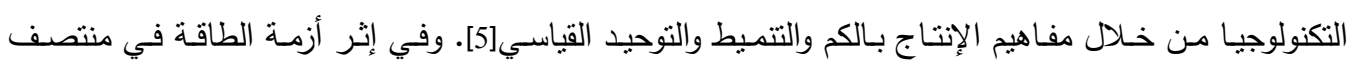

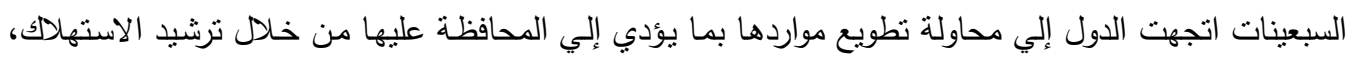

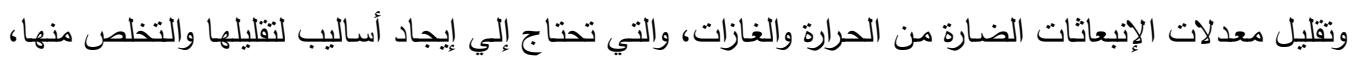

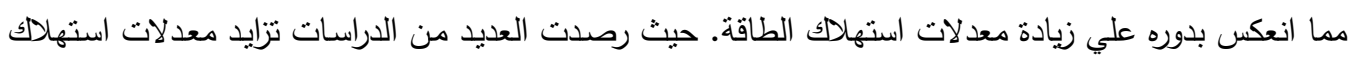

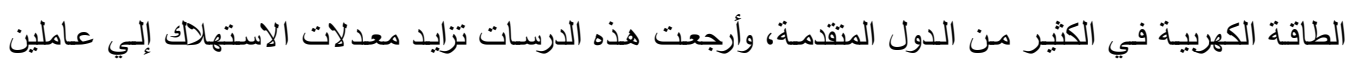

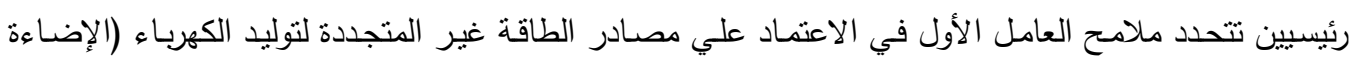

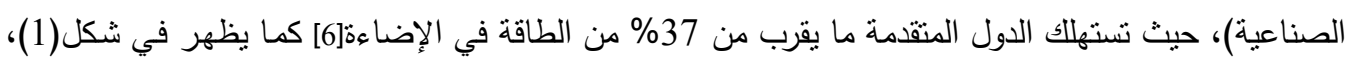

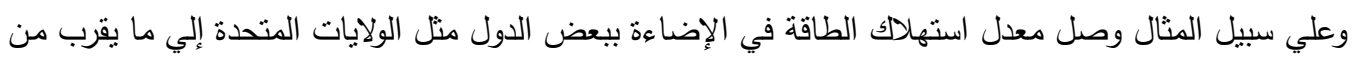

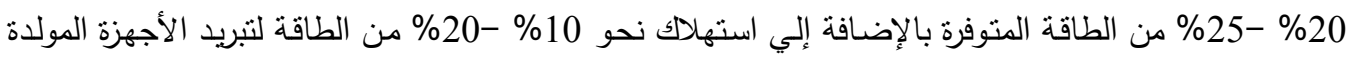

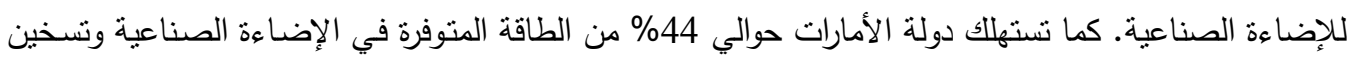

المباه[7]

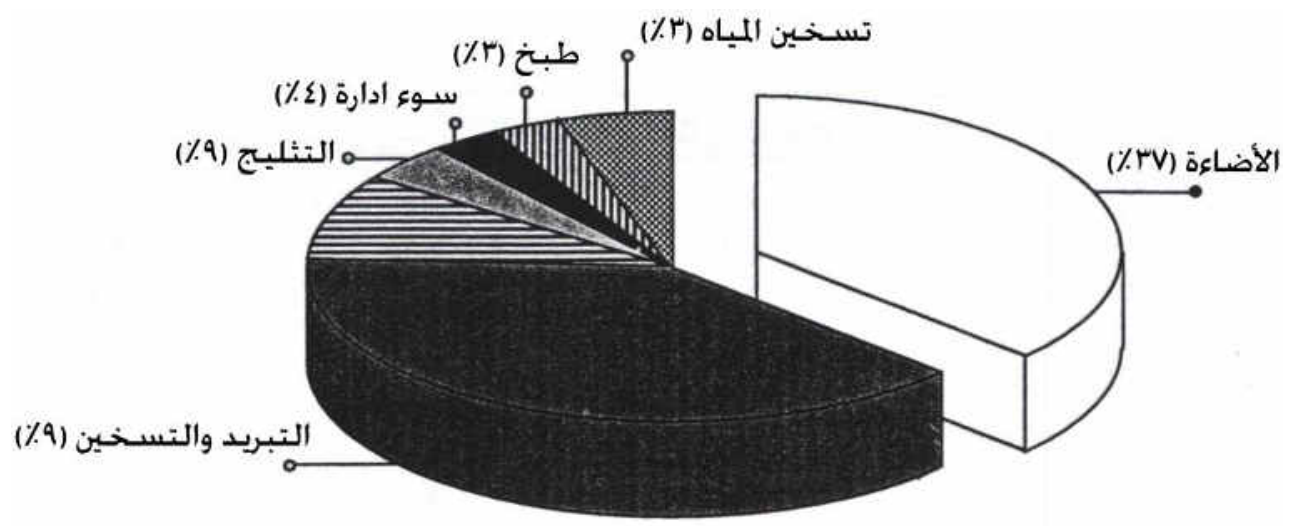

شكل(1): تتامي حجم استهلاك الطاقة في القطاعات المختلفة في الدول المتقدمة]6]

ويثكل العامل الثاني لتتامي معدل استهلاك الطاقة استخدام الأجهزة المصاحبة لتبريد مصادر الإضاءة الصناعية. حيث تصاحب الحرارة عملية إدخال الضوء مما يساهم في زيادة درجة حرارة الفراغ. وعلي سبيل المثال يحول 
المصباح المتوهج حوالي 7\% من الطاقة الكهربية إلي ضوء أما 93\% من الطاقة الكهربية فنتبعث منه بصورة

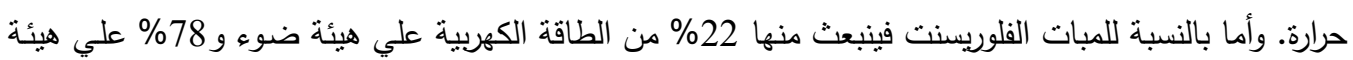

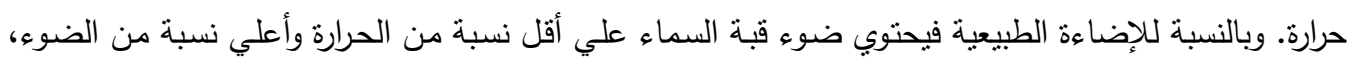

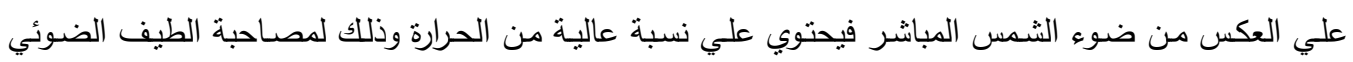

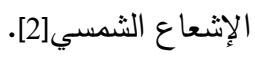

\section{2- 2 العوامل المؤثرة في تحقيق الراحة البصرية:}

تؤدي بعض العوامل علي إضفاء الراحة البصرية بالفراغ، مما ينعكس علي مستخدم الفراغ، ولتحقيق المنطلبات التي التي

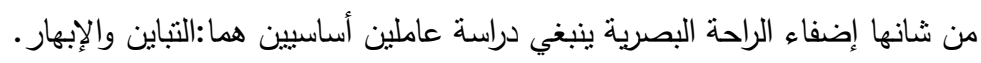
2-1-1 التباين:

يعرف المجال البصري بمجال رؤية العين والذي ينقسم إلي ثلاث مناطق رئيسية كما في شكل(2) [8]:

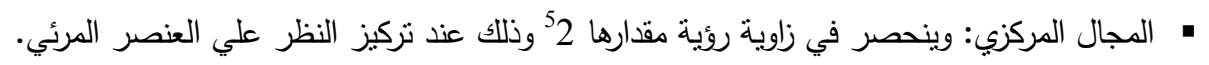

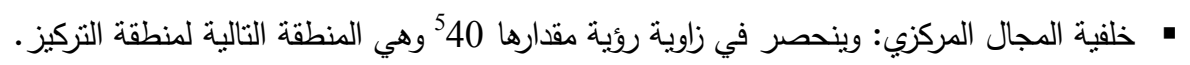

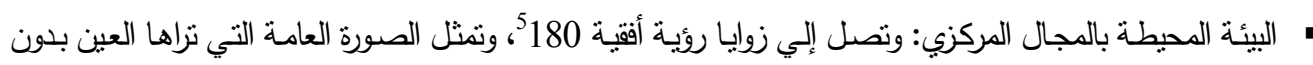

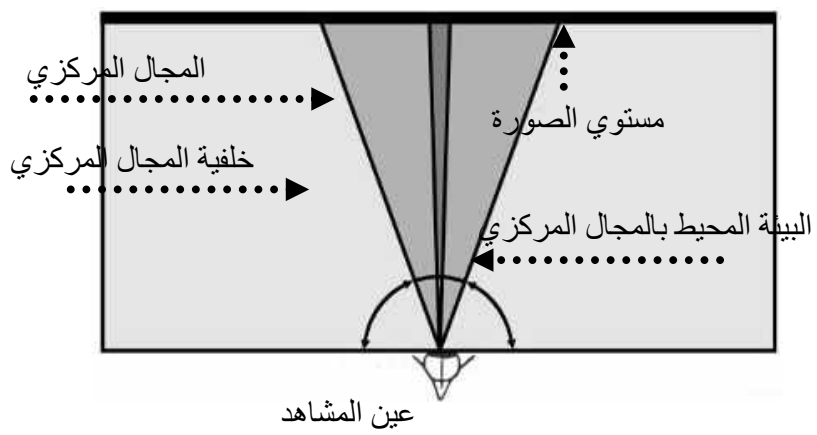
تركيز.

\section{شكل(2):}

المجــال البصــري المركـزي، خلقيـة

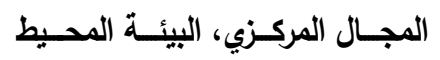
بالمجال المركزي

وتنطلب الراحة البصرية نوزيع جيد للضوء في مجال الروئية، حيث يراعى أن تكون مرجة إضاءة العنصر المرئي أعلى من

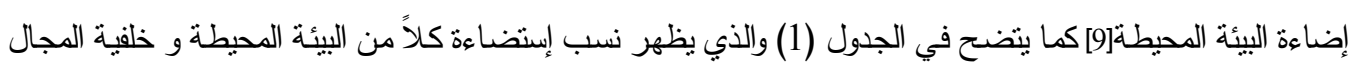
المركزي والمجال المركزي.

جدول(1) نسب التباين بين المجال المركزي، خلفية المجال المركزي، البيئة المحيطة]8]

\begin{tabular}{|c|c|c|c|}
\hline المجال المركزي & خلفية المجال المركزي & البيئة المحيطة & معدل التباين \\
\hline 5 & 2 & 1 & الحد الأكنى \\
\hline 10 & 3 & 1 & الحد الأقصى \\
\hline
\end{tabular}




\section{2-2 2-2 الإبهار:}

يعرف الإبهار بضوضاء الروية ويتمتل في عدم القدرة على الروية الجيدة[2]. وينتج الإبهار من خلال إيجاد مصدر

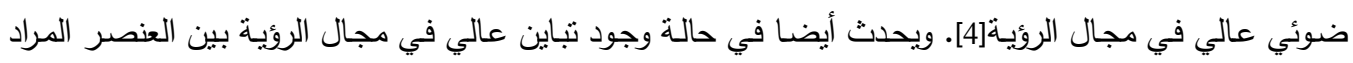

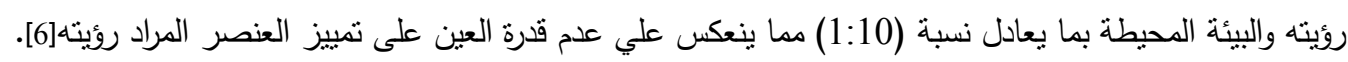

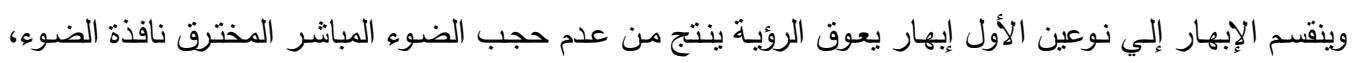

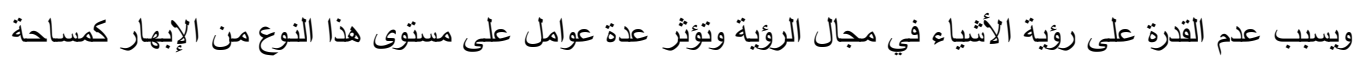

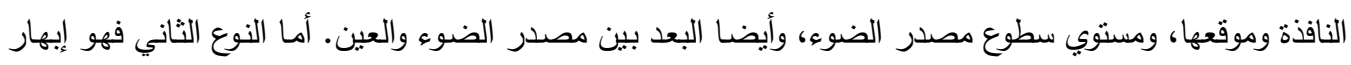

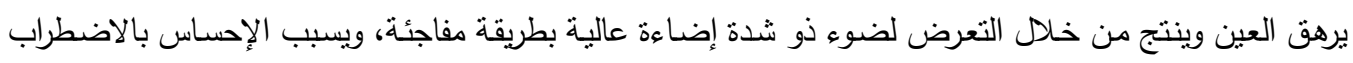
والضيق وتظل نلاك المؤثرات فترة قصيرة وتؤدى إلي تقليل قدرة الثخص على على الإبصار [4]].

\section{3- 3ركبات الإضاعة الطبيعية:}

تعتمد الإضاءة الطبيعية داخل الفراغ علي مستوي شدة الإستضاءة خارجة، حيث يكون مستوبي شدة الإستضاءة داخل

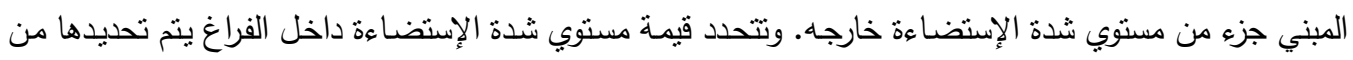

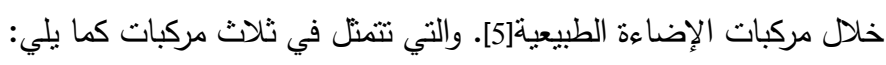

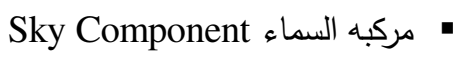

Internal Reflected Component مركبه الانعكاسات الداخلية •

• مركبه الانعكاسات الخارجية External Reflected Component

وتمتل مركبه السماء مستوي شدة الإستضاءة عند نقطة من خلاد رؤية قبة السماء المباثرة، أما مركبه الانعكاسات

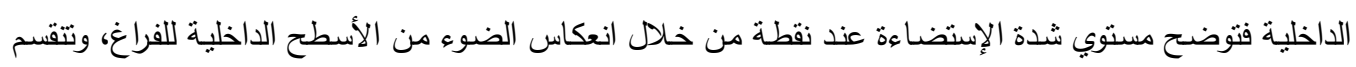

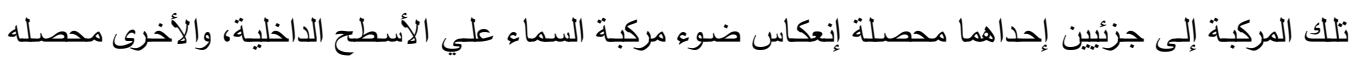

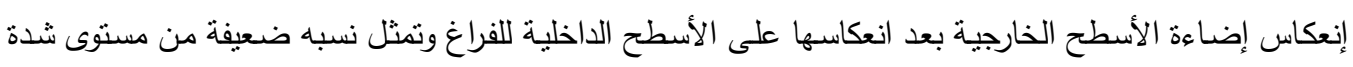

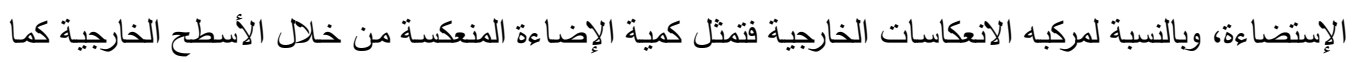

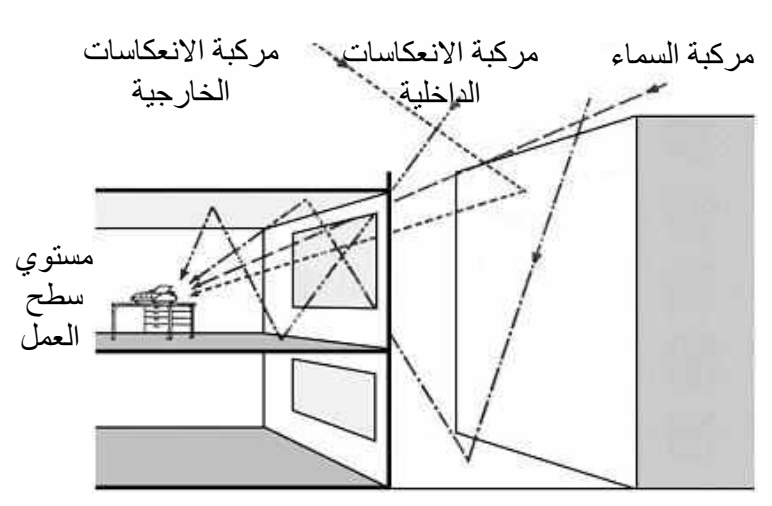

في شكل (3) [10].

شكل (3): مركبات الإضاءة الطبيعية[10]

4- الخلفية النظرية لتأثير الوسط المحيط بالمبني علي سلوك الإضاءة الطبيعية: 
تؤثز البيئة الداخلية علي سلوك الإضـاءة الطبيعية داخل فراغات المبني، حيث تعمل الأسطح الداخلية وعناصر الأثاث

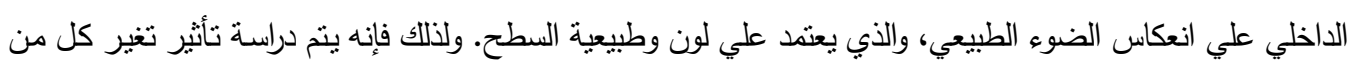
لون عناصر الأثاث الداخلي، وأيضـا لون الأسطح الداخلية للفراغ علي سلوك الإضـاءة الطبيعية داخل فراغات المبني وذلك بشكل نظري. يتمنل في استعراض ما جاء في الأبيات والأبحاث العلمية، ثم أجراء القياسات الميدانية للتحقق منه عملياً.

\section{4-4}

تمنل عناصر الفرش إحدى العوامل المؤثزة على مستوي شدة الإستضاءة ومعدل توزيعها ، حيث يؤثر كل من لون وتوزيع عناصر الفرش على كمية الإضاءة المنعكة داخل الغرف، والتي تمنل إحدى جوانب مركبة الانعكاسات الداخلية [11].

\section{2-4 2}

تمنل انعكاسات الأسطح إحدى مصادر الإضـاءة الطبيعية غير المباشرة، وكذلك إحدى مصادر تحسين الإضـاءة داخل الفراغات. وتتوقف كمية الإضاءة المنعكسة منها على معامل انعكاسات تلك الأسطح. ويوضح الجدول (2) مدي تأثير تغير ألوان الأسطح الداخلية المتمثلة في الأسقف، والحائط المقابل للنافذة، والأسطح المجاورة للنافذة، وأخيرًا أرضيات الفراغ علي توزيع الإضاءة الطبيعية داخل الفراغات[4].

ومن خـلال الدراسـة السـابقة بتضـح أن الأسقف تعد اقوي تأثنيرا على توزيـع الإضـاءة الطبيعيـة داخل الفراغ، ويليه

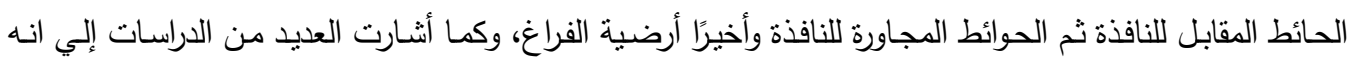
لتفعيل دور الأسطح الداخلية للمساهمة في زيادة كمية الإضاءة داخل الفراغات ينبغي تحقيق الآتي[12]. • زيادة المسافة بين السقف وسطح العمل حتى يمكن تجنب وقوع مستوى السقف في مخروط رؤية المستخدم.

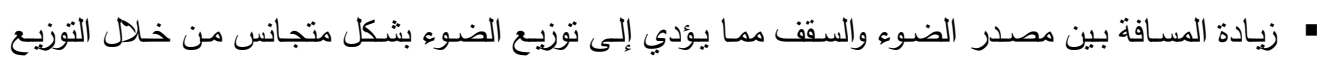
المنساوي للضوء على السقق. • استخدام أسطح ذات معامل انعكاس عالي. " استخدام النوافذ السفلية والإضاءة المنعكسة من الأرضية الخارجية كمصدر لإضاءة الفراغات. 
جدول (2): تأثير تغير ألوان الأسطح الاخلية علي توزيع الإضاعة الطيعية

\begin{tabular}{|c|c|c|}
\hline التحليل & الوصف & الحالة \\
\hline 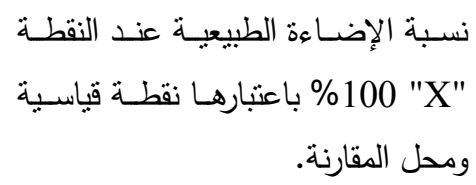 & تطاسية X بنهاية الفراغ. & \\
\hline 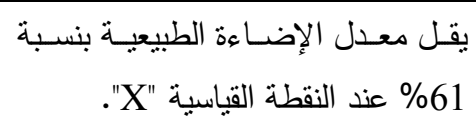 & تطلي جميع الأسطح الداخلية باللون الأبيض، ماعدا & \\
\hline 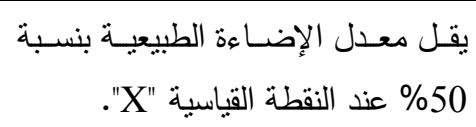 & 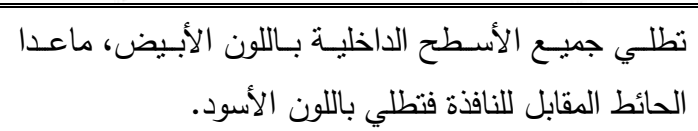 & \\
\hline 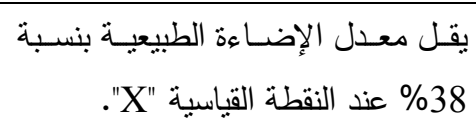 & 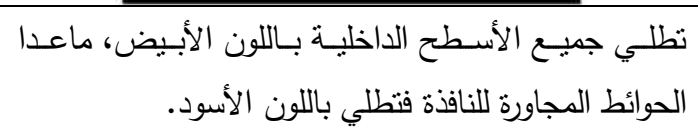 & \\
\hline 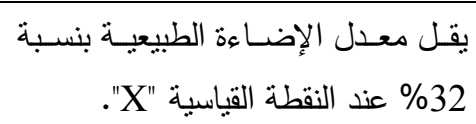 & 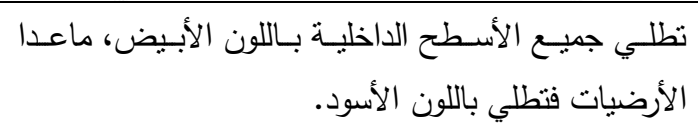 & \\
\hline
\end{tabular}




\section{5- منهجية الدراسة الميدانية:}

تعتمد الدراسة الميدانية علي العديد من المقومات، والتي تثكل في مجملها منهجية الدراسة الميدانية. حيث يتم

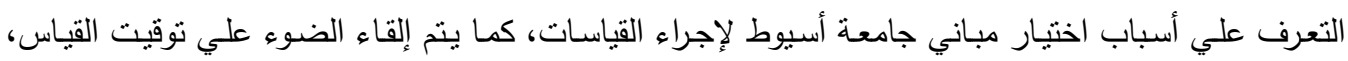

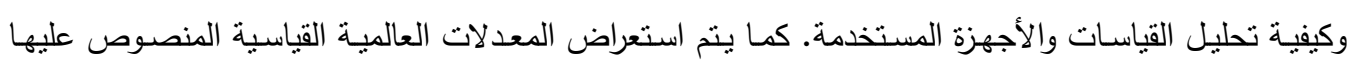
لإضاءة الفراغات التعليمية الجامعية. وذلك بهدف وضع الأسس والقواعد لتحليل نتائج القياسات الميدانية.

\section{1-5 أسباب اختيار مباني جامعة أسيوط للاراسة الميدانية:}

تثارك العديد من العوامل في دعم اختيار مباني جامعة أسيوط للاراسة الميدانية والتي يمكن تمثيلها في الآتي:

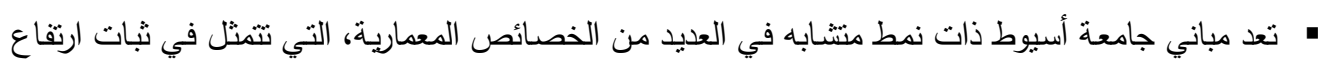

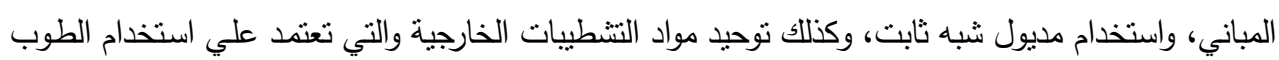

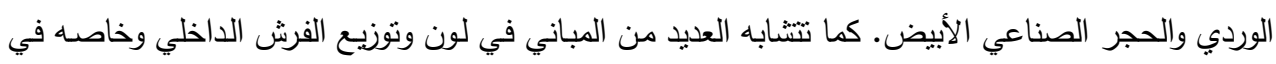

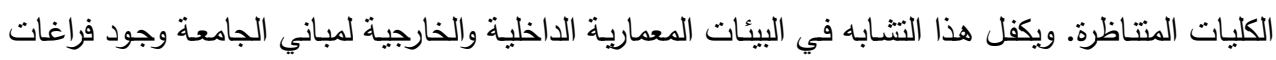
عديدة متشابه، والذي يؤدي بدوره إلي نتوع حالات الدراسة.

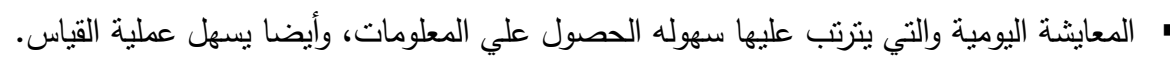

\section{2-5 محددات الدراسة الميدانية:}

تعتد الدراسة الميدانية على العيد من الدحددات. والتي تتمثل في اختيار نقاط القياس، وتوقيت القياس، وكذا أجهزه

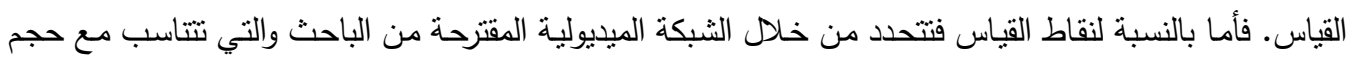

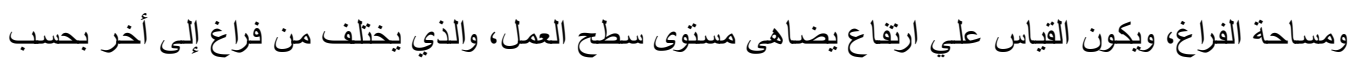

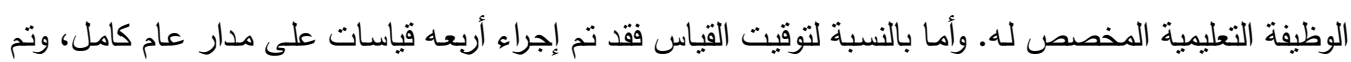

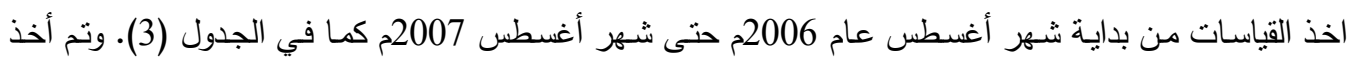

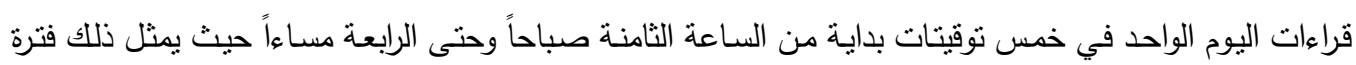

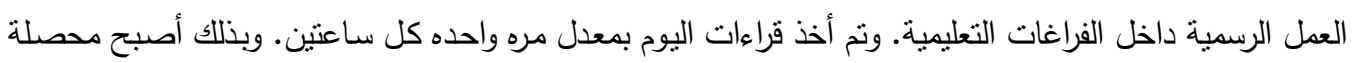
قراءات الفراغ الواحد ما يعادل عشرون قراءه، وتم أخذ منوسط هذه القياسات لتحليل نتائجها.

جدول (3) تاريخ القياسات الحقلية للقراءة الأولي والثثانية والثالثة والرابعة.

\begin{tabular}{|c|c|c|c|c|}
\hline تاريخ قياس & تاريخ قياس القراءة & تاريخ قياس القراءة & تاريخ قياس & المبني \\
\hline $2007 / 8 / 1$ & $2007 / 2 / 27$ & $2006 / 12 / 7$ & $2006 / 9 / 3$ & كلية الطب البيطري \\
\hline $2007 / 6 / 12$ & $2007 / 2 / 19$ & $2006 / 12 / 24$ & $2006 / 9 / 18$ & كلية الزراعة \\
\hline
\end{tabular}

أما بالنسبة للأجهزة المستخدمة للارسة الميدانية فيتم استخدام جهاز قياس شده الإضاءة Light Meter. والجهاز

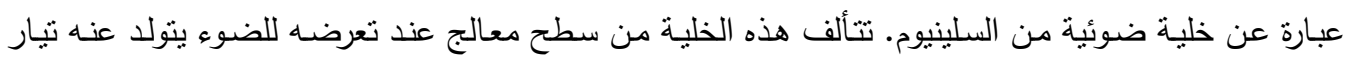




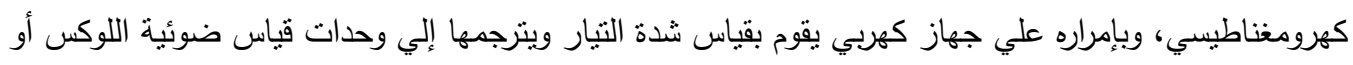
شمعة/قدم². وتم توحيد وحده القياس وهي اللوكس Lux. كما يوضح الجدول (4) نوعية ودقة الجهاز المستخدم.

جدول (4) نوعية ومدي دقة الجهاز المستخدم في قياس شدة الإستضاعة.

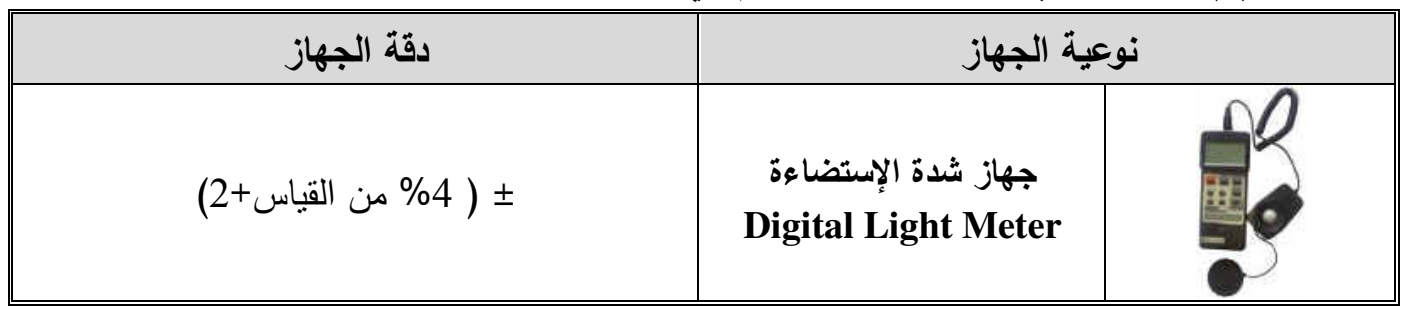

\section{3-5 3 3يفية تحليل نتائج القياسات الميدانية:}

تعتمد الدراسة الميدانية علي المقارنة بين الفراغات ذات التتابه في الخصائص المعمارية الخارجية والداخلية وذات

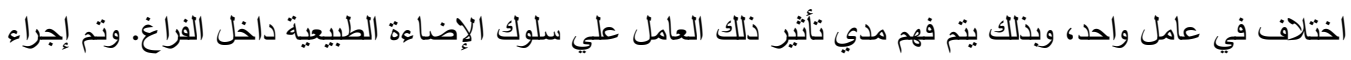

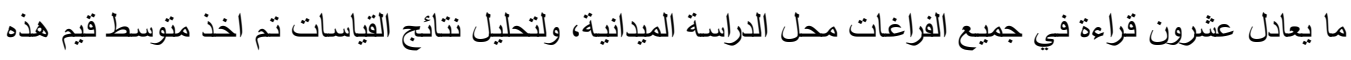

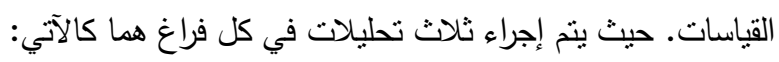

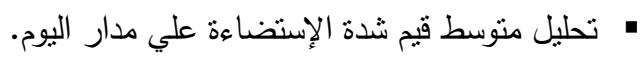

• • تحليل معدل الانتشار للضوء الطبيعي داخل الفراغ.

• تحليل معدل الاختراق للضوء الطبيعي داخل الفراغ.

فأما بالنسبة لدتوسط قيم شدة الإنتضاءة داخل الفراغ فيتم ذلك من خلال أخذ متوسطات قيم شدة الإستضاءة من

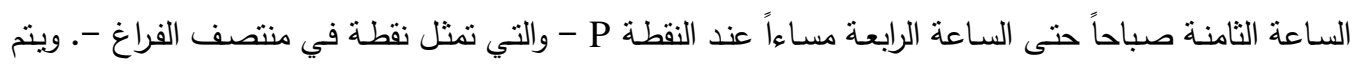
التعبير عن ذلك من خـال منحني يمثل محور X النوقيت (بالساعة)، ويمثل محور Y مستوي شدة الإستضاءة

مقاسه باللوكس Lux.

أما بالنسبة لمعدل الانتتار للضوء الطبيعي والذي يعرف بمعدل توزيع الإضـاءة الطبيعية في المسقط الأفقي (كنتور

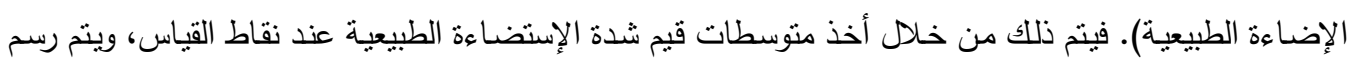

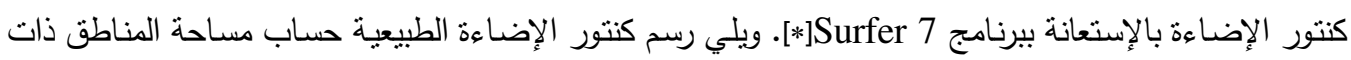

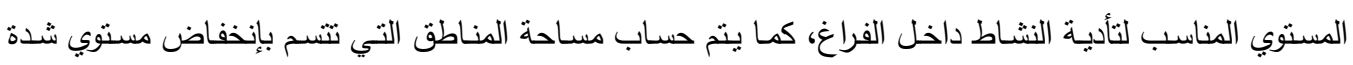

الإنتضاءة.

أما بالنسبة إلي معدل اختراق الإضاءة الطبيعية والذي يعرف بمعدل توزيع الإضـاءة الطبيعية في القطاع الراسي.

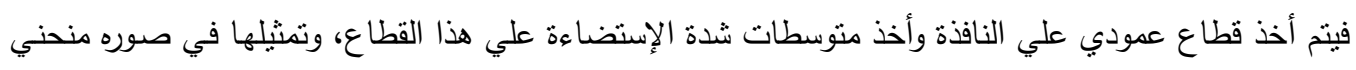

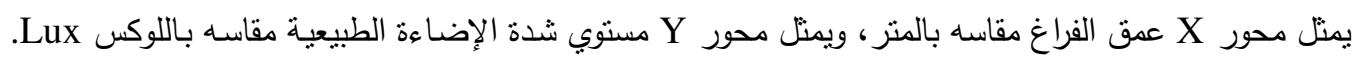

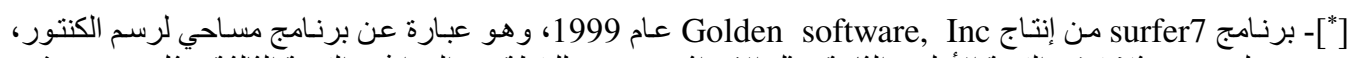

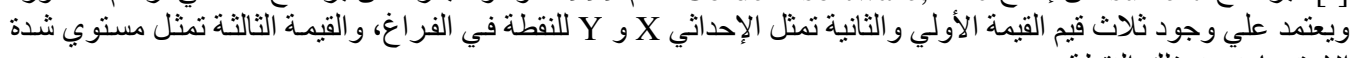


ولتحليل القياسات كان ينبغي معرفة الحد الادني لإضـاءة الفراغات التعليمية الجامعية والتي سوف يتم مقارنـة النتائج بها. والتي يمكن توضيحها في الجدول (3). والذي يظهر الحد الأدني لمستوي شدة الإنتضاءة المائائم لوظيفة كل فراغ.

جدول (3) الحد الأدني لمستوي شدة الإستضاءة المسموح به داخل الفراغات التعليمية:

\begin{tabular}{|c|c|c|}
\hline ملاحظات & الحد الادني لمستوي شدة الإستضاءة مقاسه & 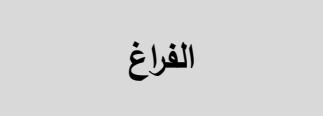 \\
\hline \multirow{7}{*}{ 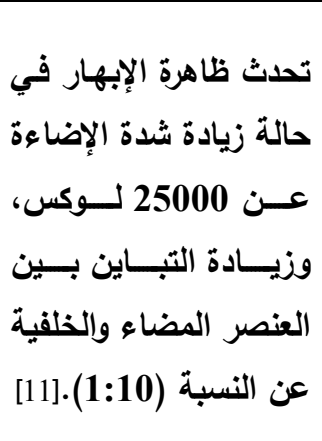 } & 1000 & قاعة رسم حر \\
\hline & 1000 & قاعات استذكار \\
\hline & 1000 & قاعة محاضرات للشرح \\
\hline & 500 & فصل دراسي \\
\hline & 500 & مختبر علمي \\
\hline & 500 & قاعة محاضرات للاستماع \\
\hline & 100 & معارض \\
\hline
\end{tabular}

6- تحليل القياسات الضوئية للمباني المختارة:

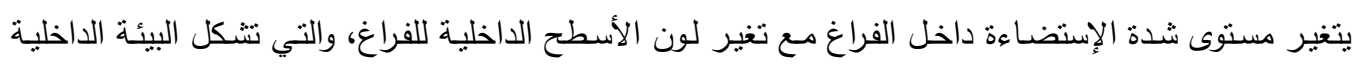

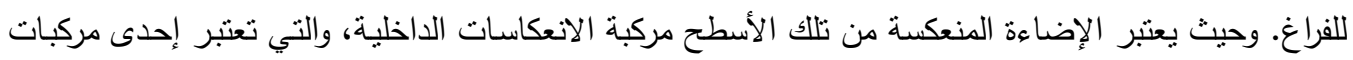

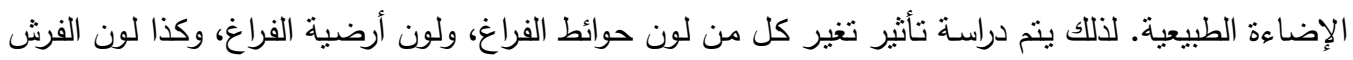

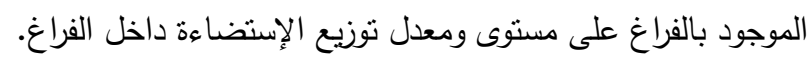

\section{1-6}

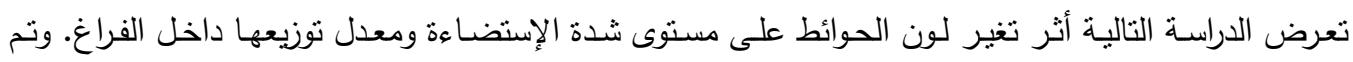

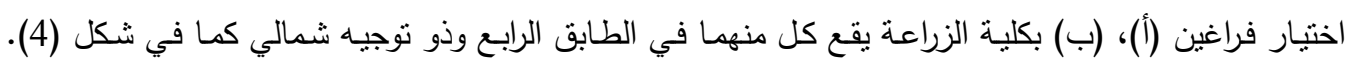
ويتشابه كل الفراغين في السمات الخارجية والداخلية. حيث يطل كل منهما على الفناء الداخلي للمبنى ويواجهه كل

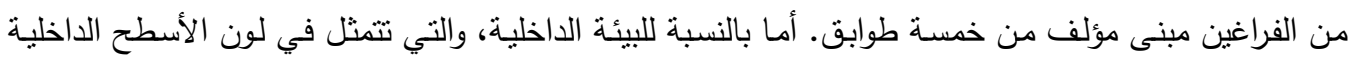

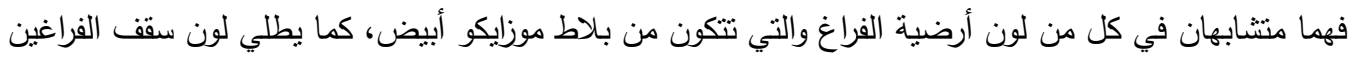

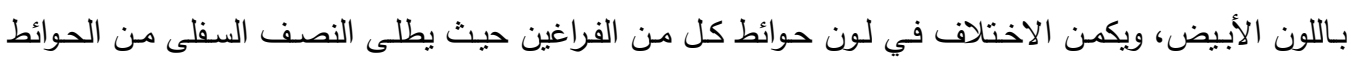

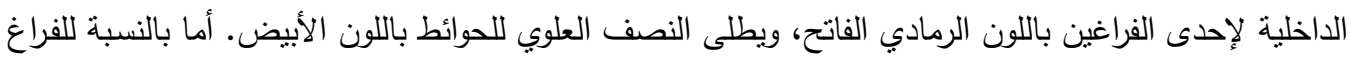

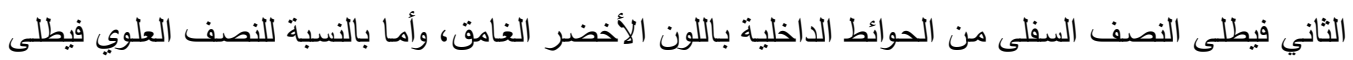

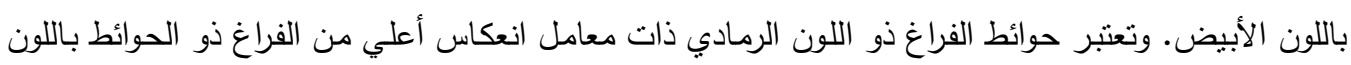

الأخضر الغامق كما يتضح في جدول (4). 
جدول(4) الخصائص الداخلية للقراغين (أ، ب) محل الاراسة الميدانية:

\begin{tabular}{|c|c|c|c|c|c|}
\hline ملاحظات & لون الفرش & لون الأسقف & لون الحوائط & لون الأرضية & اسم الفراغ \\
\hline \multirow{5}{*}{ في لون الحوائط. } & مطلــي بـاللون & تطلـــي بــاللون & تطلـــي بــاللون & بــلاط موزايكــو & \multirow{2}{*}{ أ } \\
\hline & الأبيض & الأبيض. & الرمادي الفاتح. & أبيض & \\
\hline & مطلــى بـاللون & تطلـــي بـــاللون & تطلـــي بــــاللون & بــلاط موزايكــو & \multirow{3}{*}{ ب ب } \\
\hline & الأبيض & الأبيض. & الأخضـــــــــر & أبيض & \\
\hline & & & الغامق. & & \\
\hline
\end{tabular}

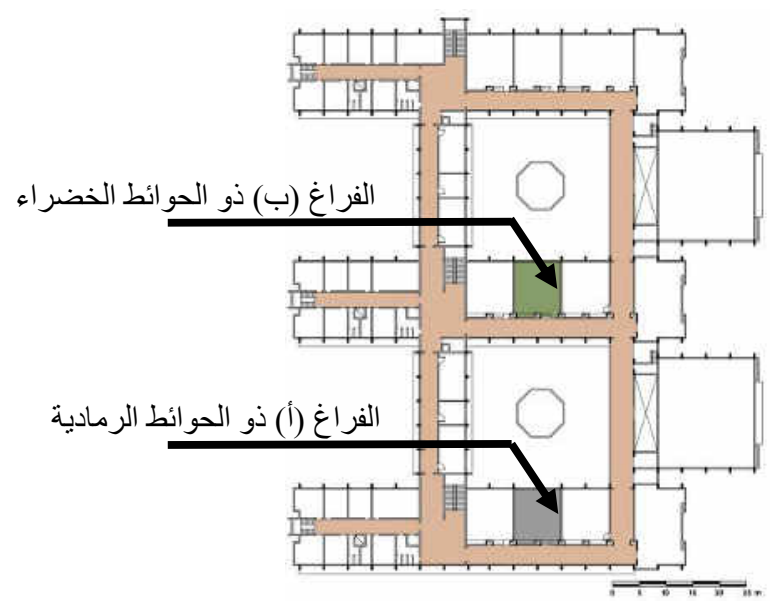

المسقط الأفقي لللدور الأول بكلية الزراعة موضح عليه الفراغين محل الدراسة الميدانية
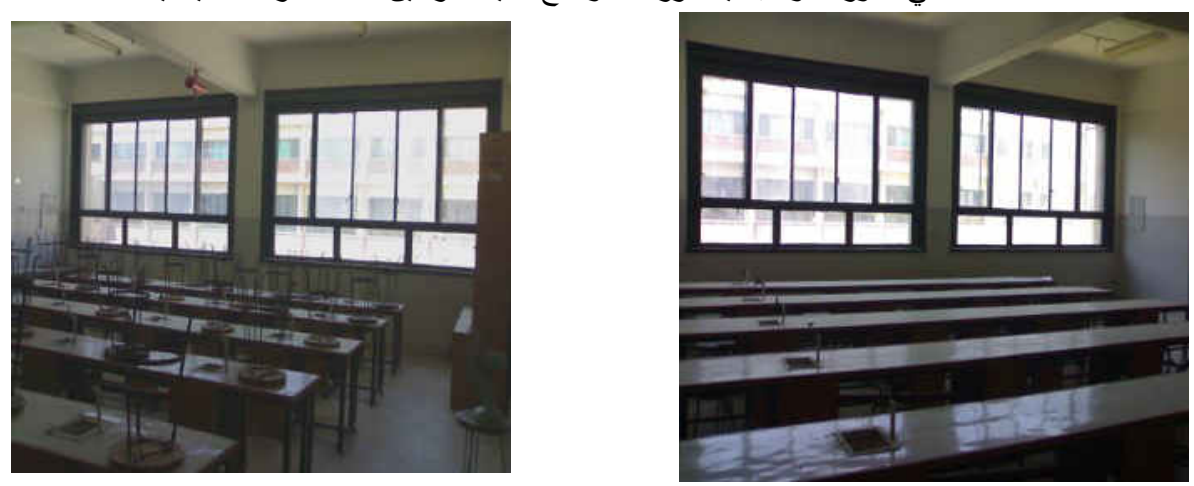

لقطة فوتوغرافية للفراغ (ب) ذو الحوائط الأخضر لقطة فوتوغرافية للفراغ (أ) ذو الحوائط الرمادي شكل (4): المسقط الأفقي ولقطات فوتوغرافية للفراغين (أ، ب) محل الدراسة الميدانية • تحليل نتائج القياسات:

يوضح الثكل (5) منوسط قيم شدة الإسنضاءة على مدار اليوم الواحد مقاسه عند النقطة P. حيث بظهر زيادة منوسط شدة

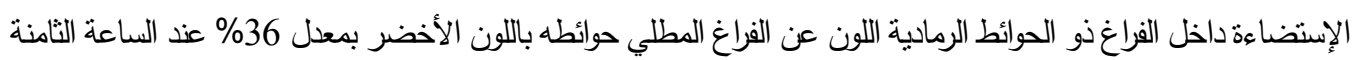


صباحاً، ويقل هذا المعلل حتى يصل عذد الساعة الرابعة مساءاً إلى ما يعادل 29\%. كما يلاحظ من الثكل عدم تحقيق كل الفراغين إلي الحد الانني لإستضاءة الفراغات التعليمية وهو 500 لوكس باعنبار أن الفراغات نستخدم كمعامل ونلك علي مدار اليوم.
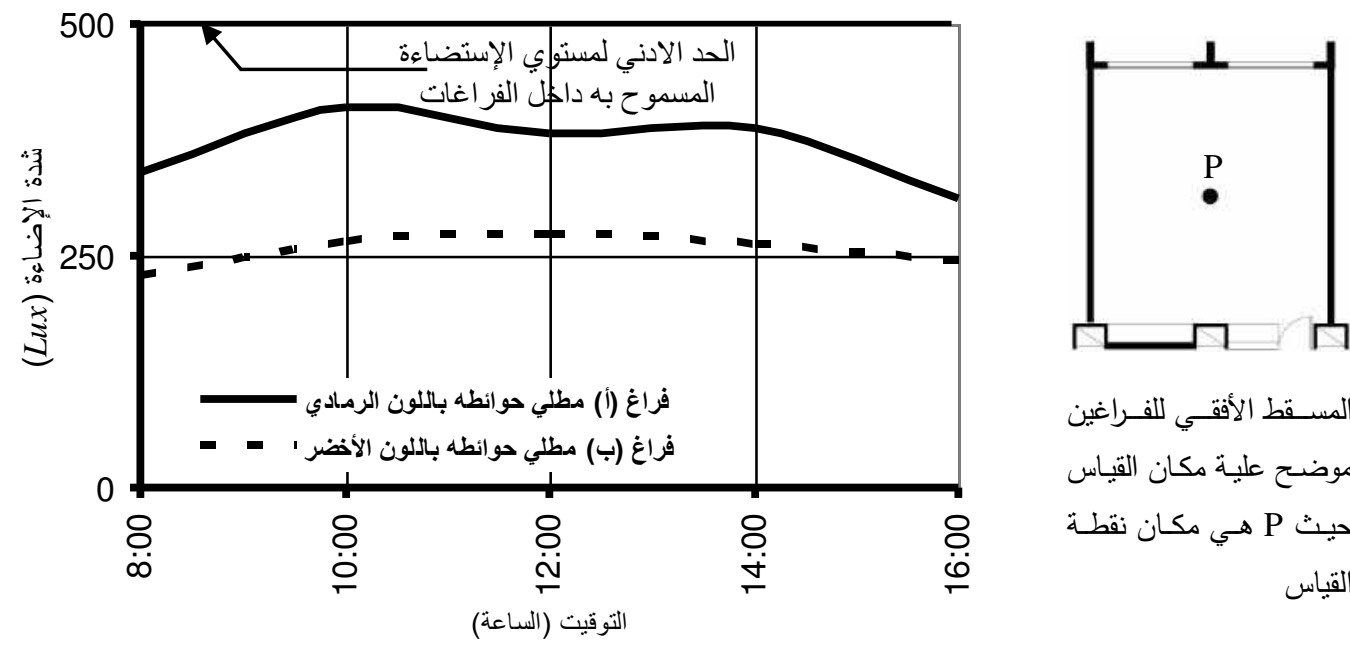

المسـقط الأفقـي للفــراغين موضح علية مكان القياس حيث Pـي مكان نقطـة القياس

\section{شكل (5): متوسط شدة الإستضاءة داخل الفراغين (أ، ب) محل القياسات الميدانية}

كما يوضح الشكل (6) معدل الانتشار للضوء الطبيعي والذي يتمثل بخطوط الكنتور ، والتي تظهر مستوي شدة الإستضاءة في المناطق المختلفة بالفراغ. ومن خلال تحليل معدل الانتشار في حالة الفراغ ذو الحوائط الخضراء

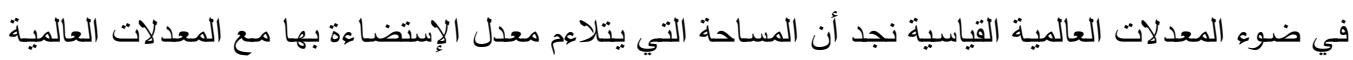
تعادل18.10\% من مساحة الفراغ الكلي، أما المنطقة ذات المستوي المنخفض فتبلغ 81.90\% من مساحة الفراغ

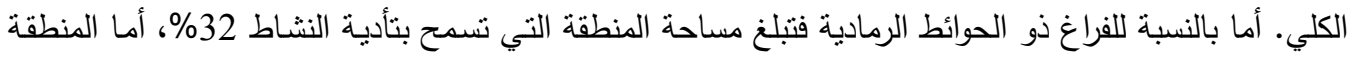

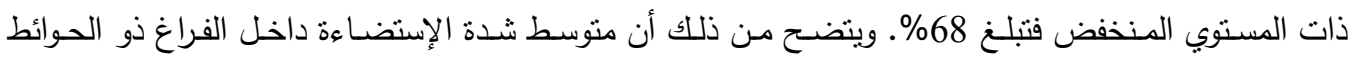
الرمادية اعلي من منوسط شدة الإستضاءة داخل الفراغ ذو الحوائط الخضراء. 


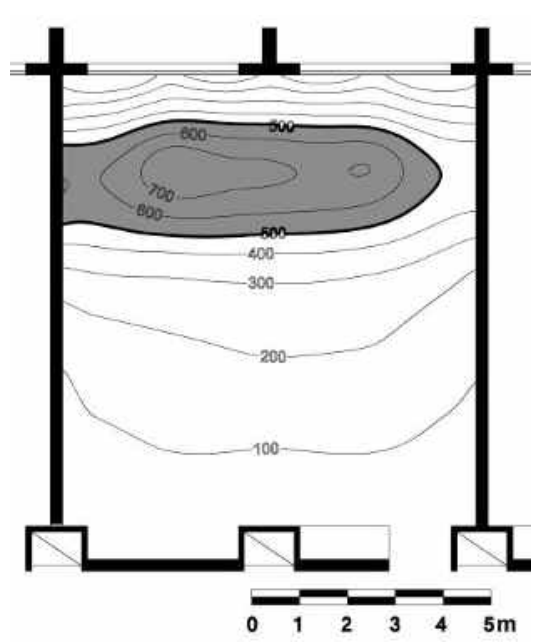

كنتور الإضاءة الطبيعية في حالة الفراغ (ب) ذو الحوائط الخضراء

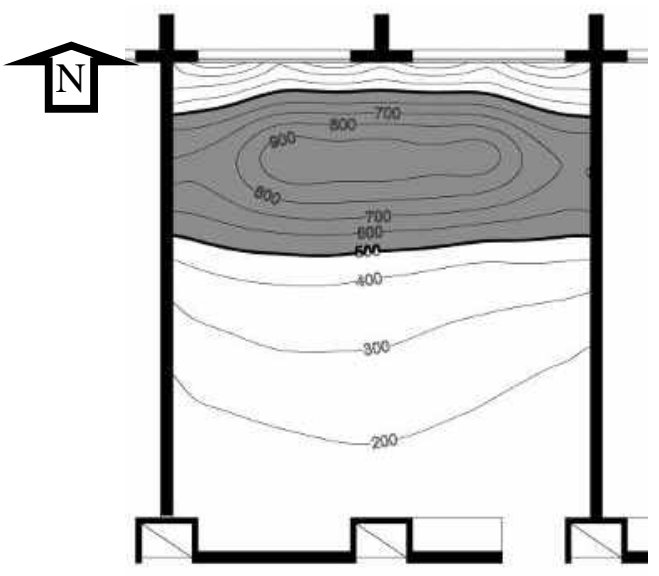

كنتور الإضاءة الطبيعية في حالة الفراغ (أ) ذو الحوائط الرمادية

شكل (6): معدل انتثار الإضاءة الطبيعية داخل كلا الفراغين (أ، ب)

أما بالنسبة لمعدل الاختراق فيأخذ الهنحنيين نفس الثكل كما ينضح في الثكل (7)، حيث يزداد مستوى الإستضاءة في حالة الفراغ ذو الحوائط الرمادية عن الفراغ ذو الحوائط الخضراء بمعدل Lux133 وذلك عند الفئ النقاط المجاورة

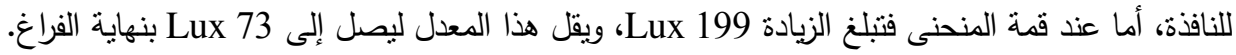

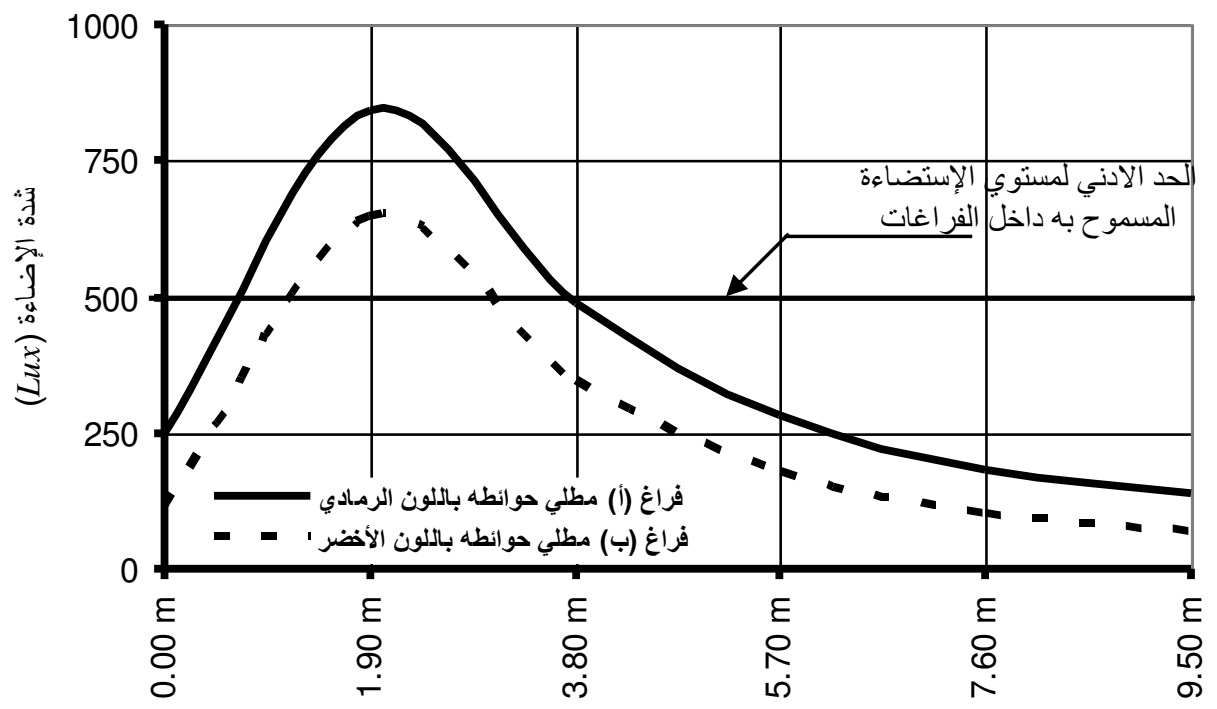

عمق الفراغ (بالمتر)

شكل (7): معدل اخترلق الإضاءة الطبيعية في الفراغين (أ، ب) محل الدراسة الميدانية 2-6 
تتتاول الدراسة الثالية أثر تغير لون أرضية الفراغ على مستوى شدة الإسنضاءة ومعدل توزيعها داخل الفراغ. حيث تم

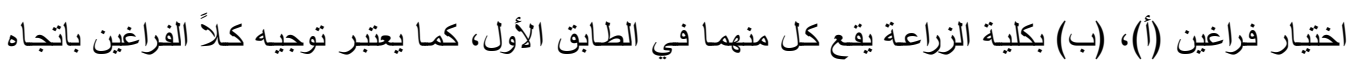

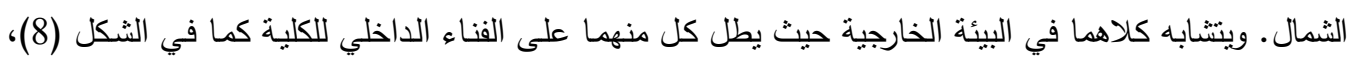
ويواجه كل من الفراغين مبنى بارتفاع خمسة طوابق كما يجاور كل من الفراغين مبنى يتألف من ثناثلاث طابقابقين.

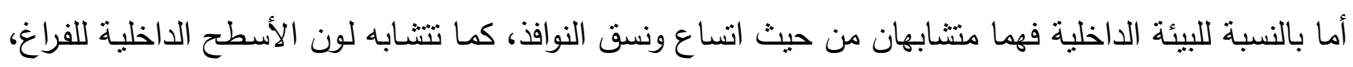

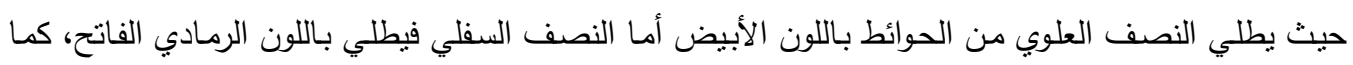

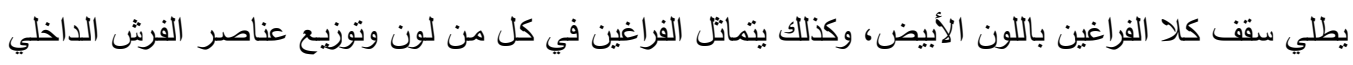

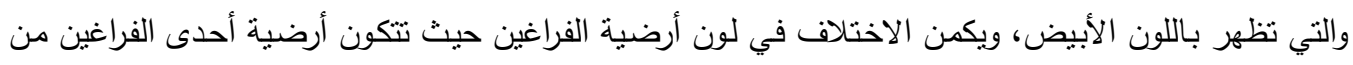

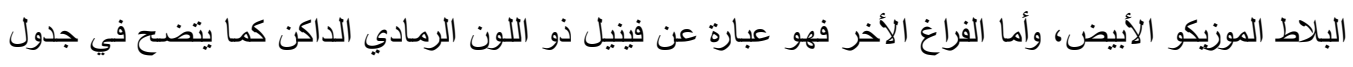

جدول(5) الخصائص الداخلية للفراغين (ج)، (د) محل الاراسة:

\begin{tabular}{|c|c|c|c|c|c|}
\hline ملاحظات & لون الفرش & لون الأسقف & لون الحوائط & لون الأرضية & اسم الفراغ \\
\hline \multirow{3}{*}{ الأرضيـية لــــــــن } & يظهــر بـاللون & تطلـــي بـــاللون & تطلــي بــاللون & بــلاط موزايكـــو & \\
\hline & الأحمر & الأبيض. & الرمادي الفاتح. & أبيض & e \\
\hline & الأحمر بــر بـاللون & تطأبلـي بـــاللون & تطلـــي بــاللون & فينيـل ذو اللـون & د \\
\hline
\end{tabular}

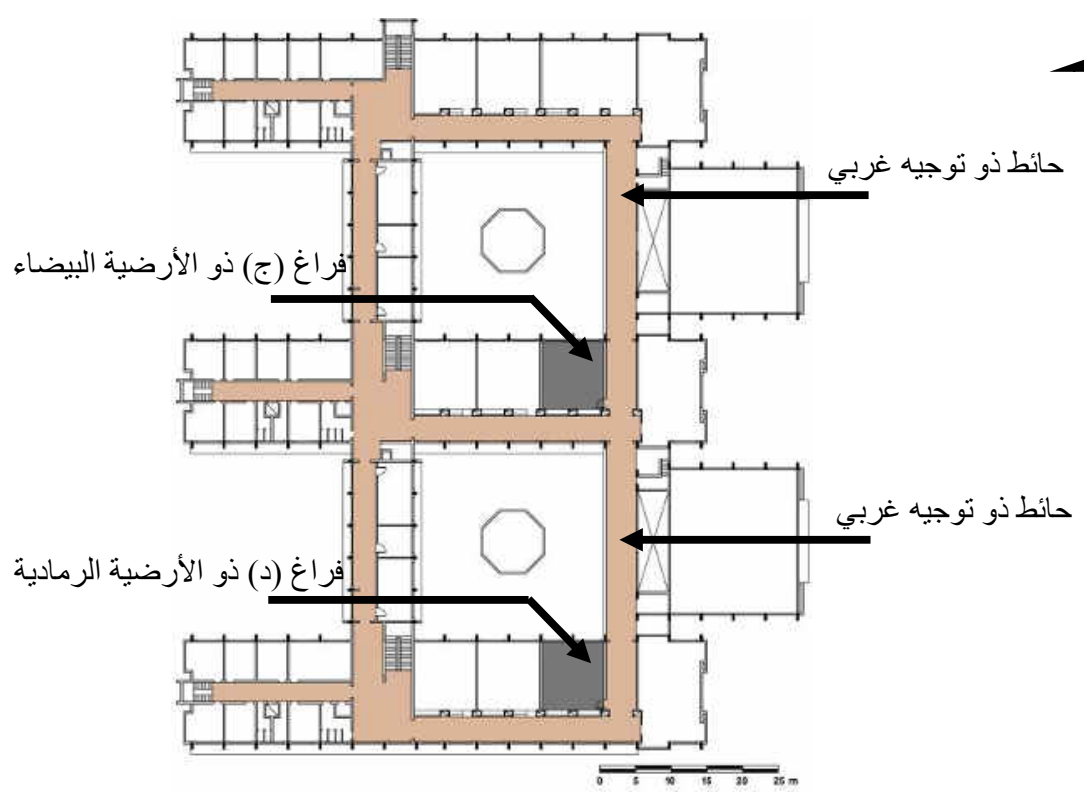

المسقط الأفقي للدور الأول بكلية الزراعة موضح عليه الفراغين محل الدراسة الميدانية 


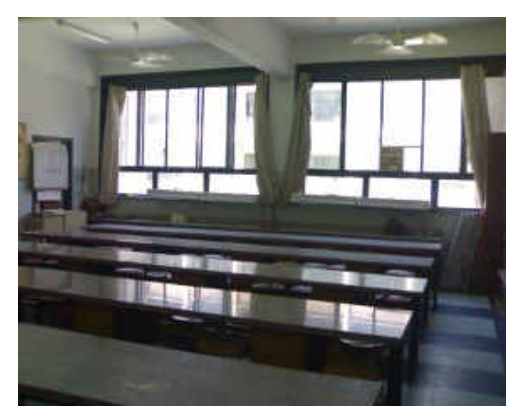

لقطة فوتوغرافية للفراغ (د) ذو الأرضية الرمادية

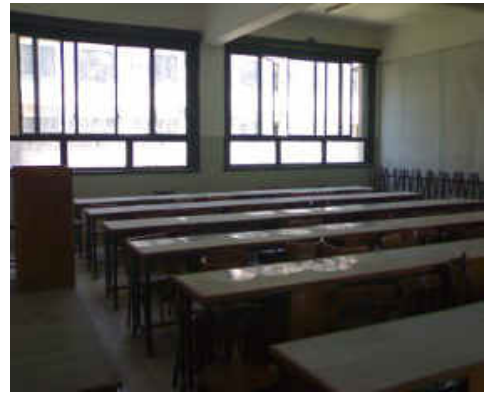

لقطة فوتوغرافية للفراغ (ج) ذو الأرضية البيضاء

شكل (8): المسقط الأفقي ولقطات فوتوغرافية للفراغين (ج)، (د) الأرغاء

\section{• تحليل نتائج القياسات:}

يستعرض الثكل (9) منوسط قيم شدة الإستضاءة على مدار اليوم مقاسه عند النقطة P. وبتحليل الثكل نالاحظ

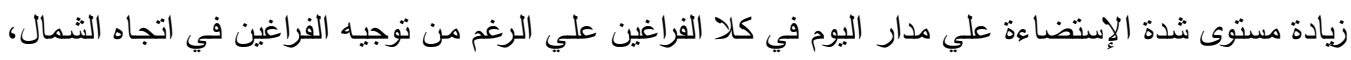

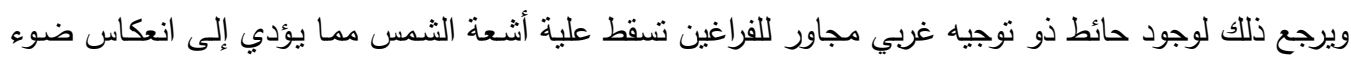

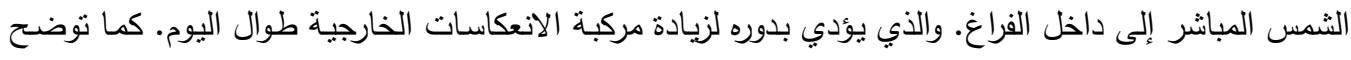

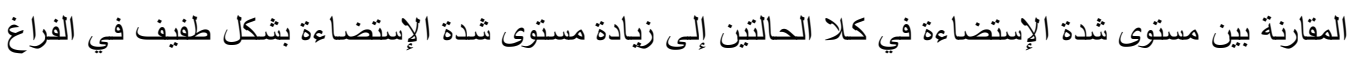

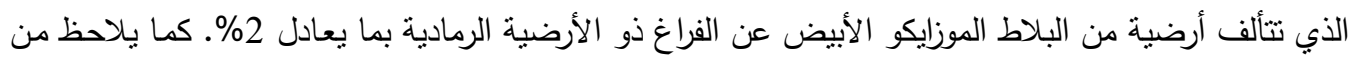

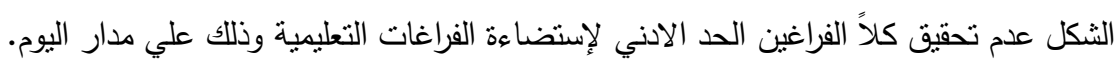

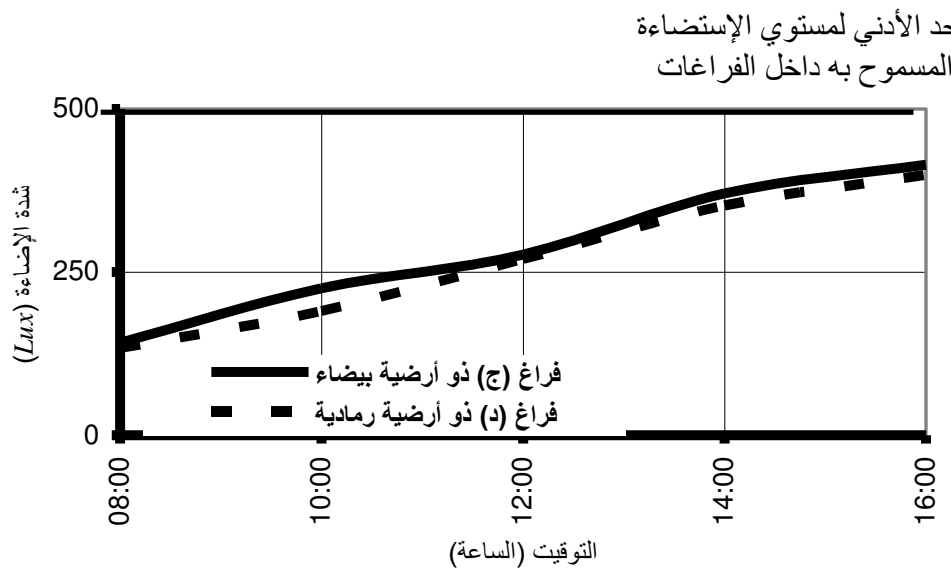

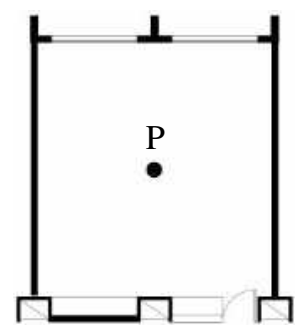

المسقط الأفقي للفراغين موضسح عليـة مكسان

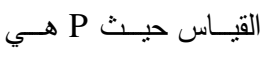
مكان نقطة القيا

شكل (9): متوسط شدة الإضاءة علي مدار اليوم بالفراغين (ج، د)

كما يوضح الثنكل (10) معدل الانتشار لكلتا الحالتين محل الدراسـة الميدانية. حيث بتضـح من خـال تحليل معدل

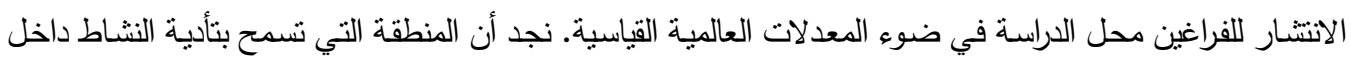

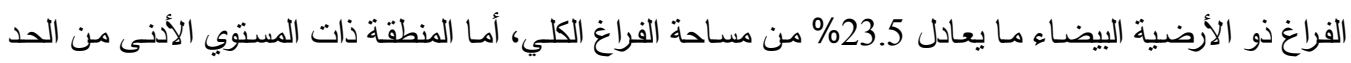

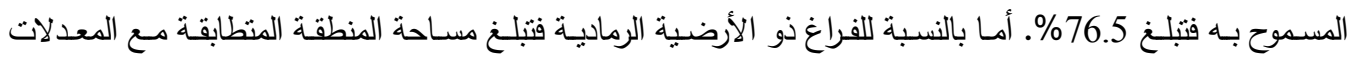




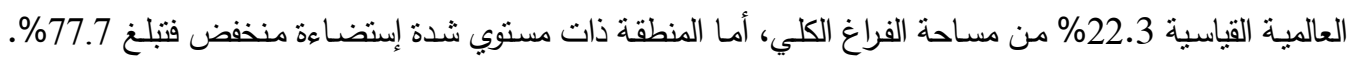

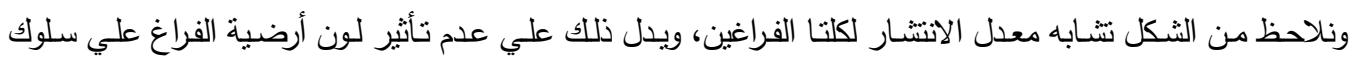
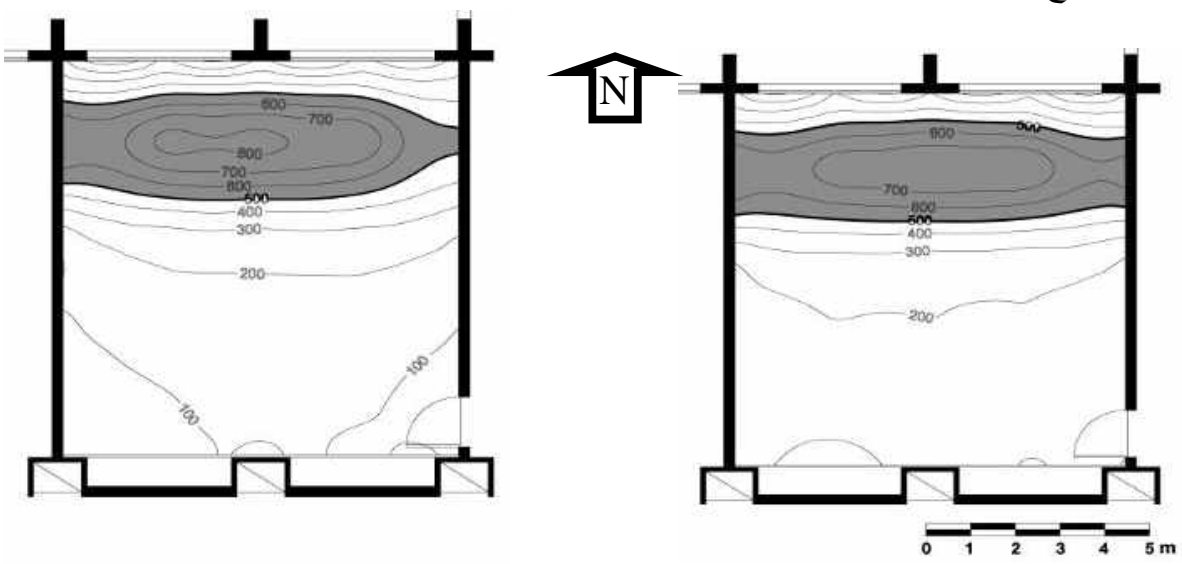

كتتور الإضاءة الطييعية في حالة الفراغ (ج) ذو الأرضية البيضاء كتتور الإضاءة الطييعية في حالة الفراغ (د) ذو الأرضية الرمادية

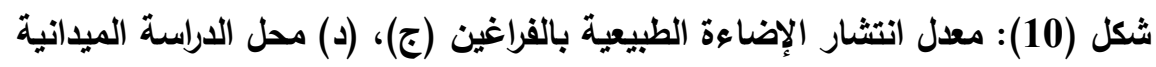

أما بالنسبة لمعدل اختراق الإضاءة الطبيعية في كلتا الفراغين فهما منطابقين. حيث بأخذ المنحنى نفس الثكل في

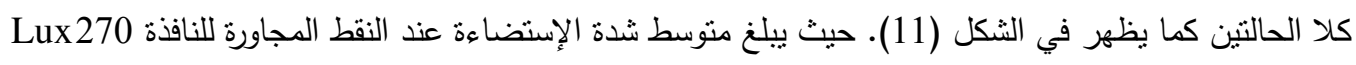

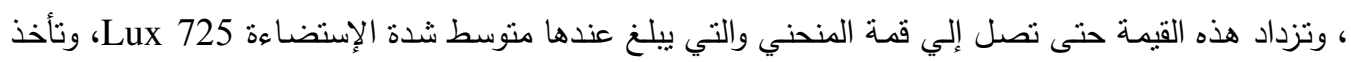

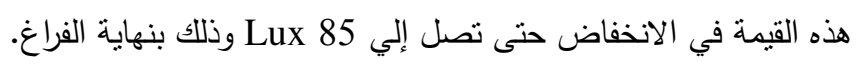

\section{3-6 ت تأثير تغير لون عناصر الفرش الاخلي:}

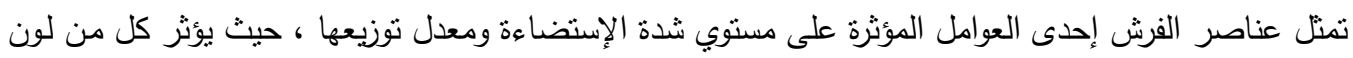

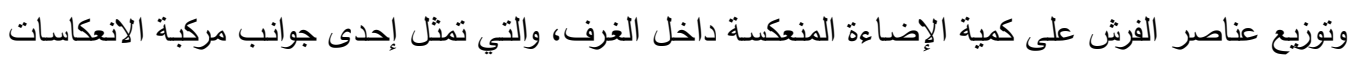

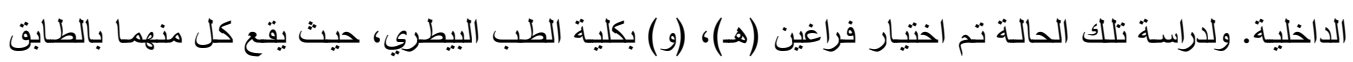

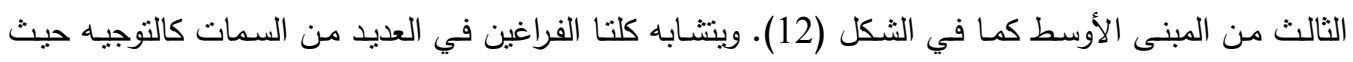

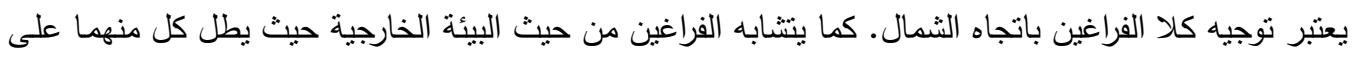

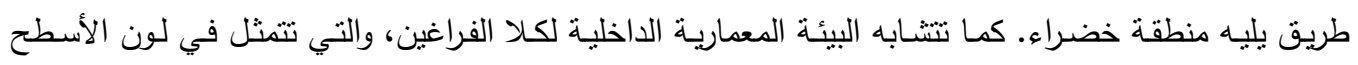

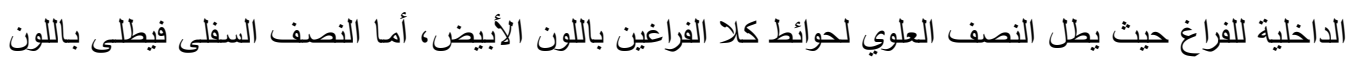

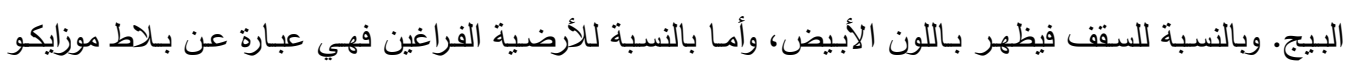

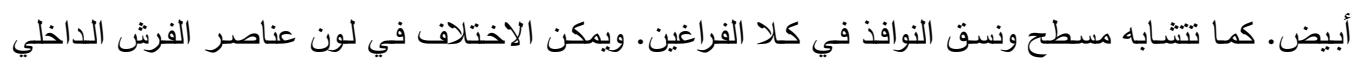

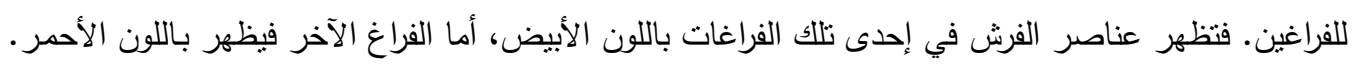

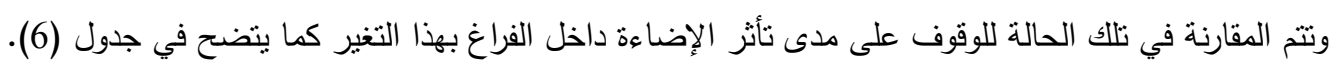




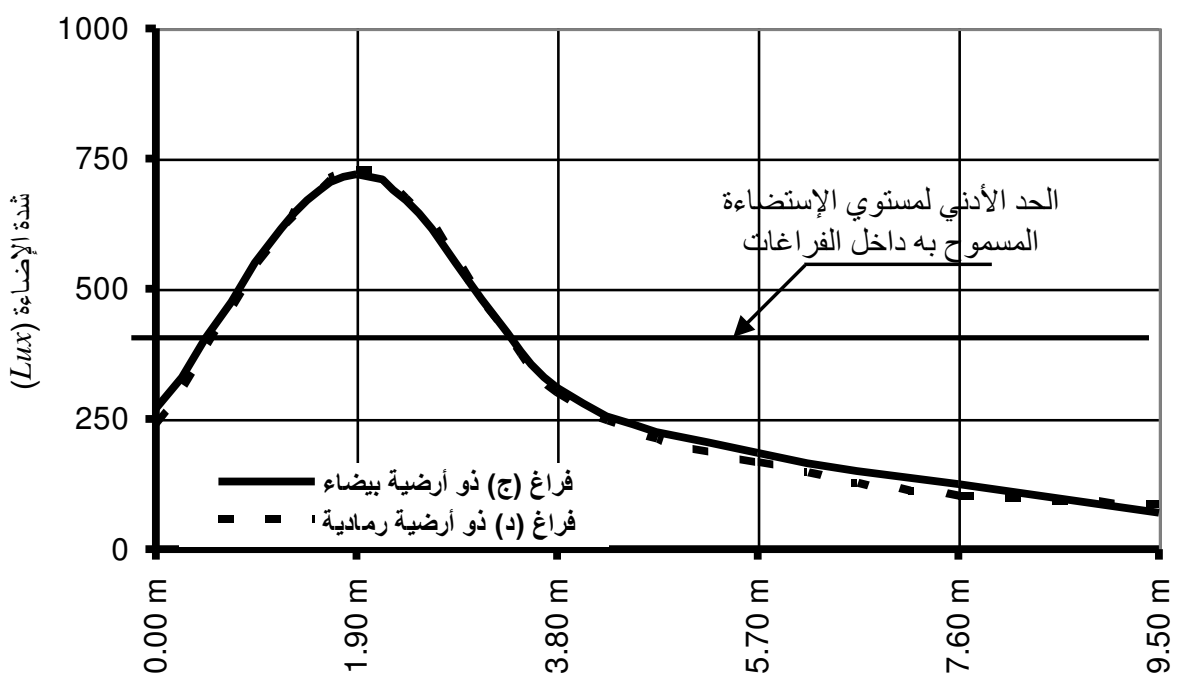

عمق القر اغ (بالمتر)

شكل (11): معدل الاخترلق للإضاءة الطبيعية بالفراغين (ج)، (د)

جدول(6) الخصائص البيئة الداخلية للفراغين (ه، و) محل الدراسة الميدانية:

\begin{tabular}{|c|c|c|c|c|c|}
\hline ملاحظات & لون الفرش & لون الأسقف & لون الحوائط & لون الأرضية & اسم الفراغ \\
\hline \multirow{2}{*}{ 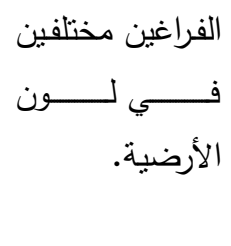 } & ذو لون ابيض & تطلــــــــاللون & تطلـــــــــاللون & بـــلاط موزايكـــو & هـ \\
\hline & ذو لون احمر & تطلــي بــاللون & تطادلــي بــاللون & بــــلاط موزايكـــو & 9 \\
\hline
\end{tabular}

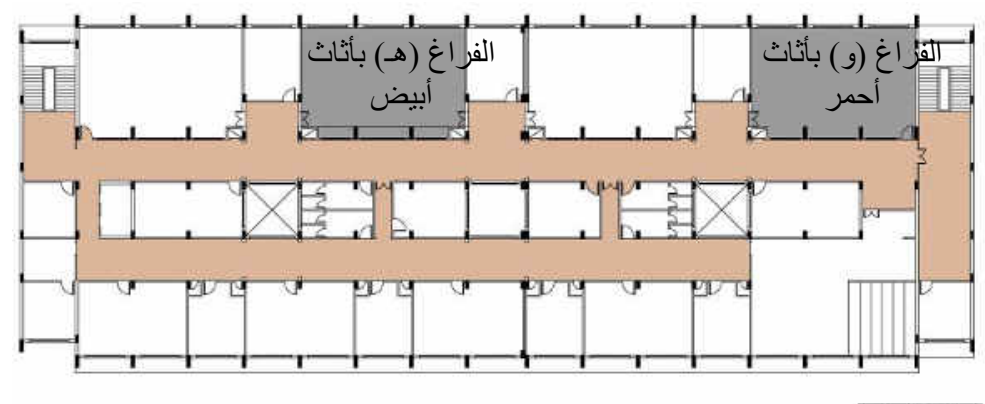

المسقط الأفقي للدور الثالث بكلية الطب البيطري موضح عليه الفراغين محل الدراسة الميدانية 


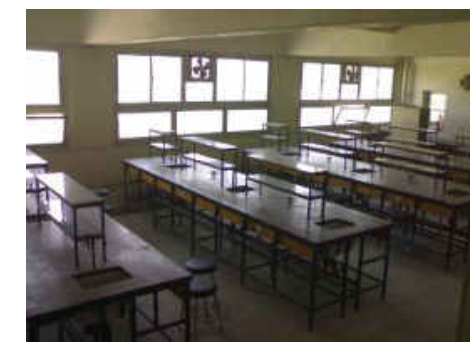

لقطة فوتوغرافية في الفراغ (و) ذو أثاث أحمر

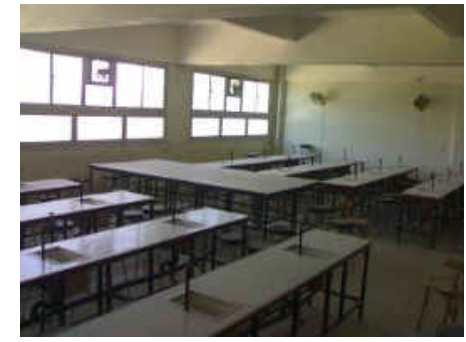

لقطة فوتوغرافية في الفراغ (هـ) ذو أثناث أبيض

شكل (12): المسقط الأفقي ولقطات فوتوغرافية للقراغين محل الدراسة الميدانية

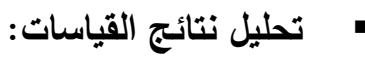

يوضح الثكل (13) متوسط قيم شدة الإستضاءة على مدار اليوم الواحد مقاسه عند النقطة P. حيث يظهر زيادة

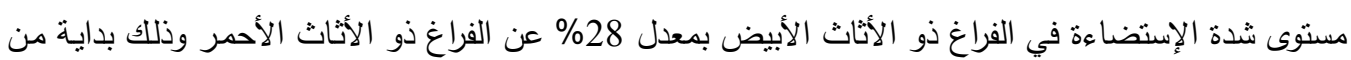

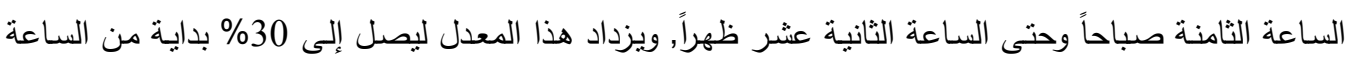

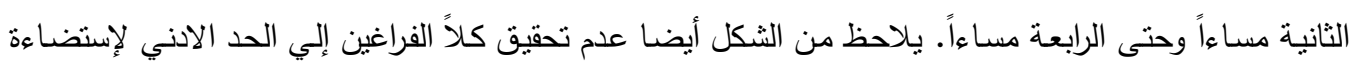
الفراغات التعليمية وذلك علي مدار اليوم.
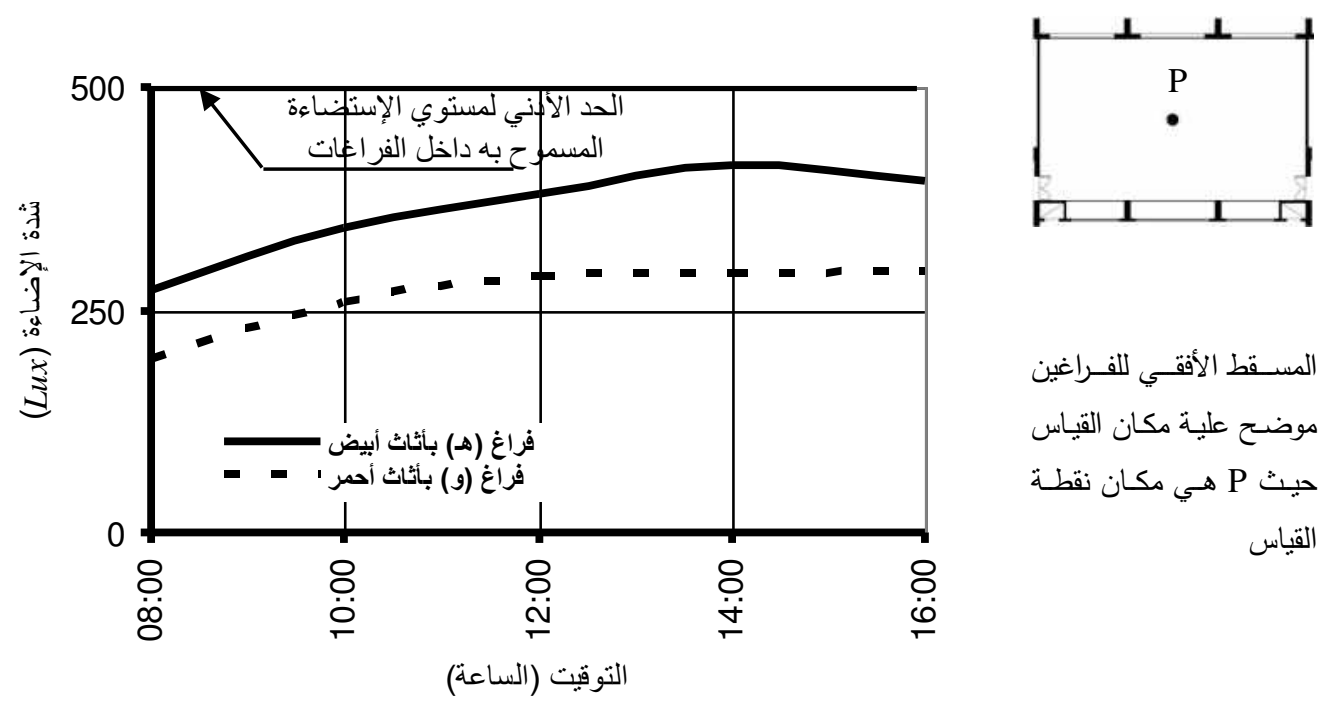

المسـقط الأفقـي للفــراغين موضح علية مكان القياس

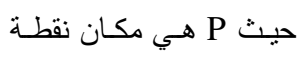
القياس

شكل (13): متوسط شدة الإستضاءة للفراغين (ه)، (و) محل القياسات

كما يوضح الثكل (14) معدل الانتشار للإضاءة الطبيعية في كلا الفراغين. حيث يتضح أن المنطقة التي تصلح

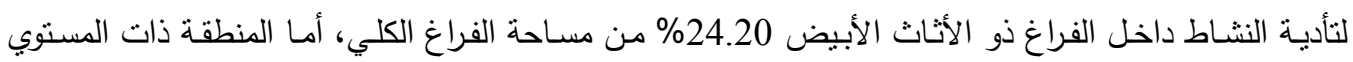

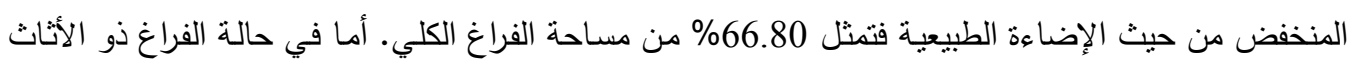

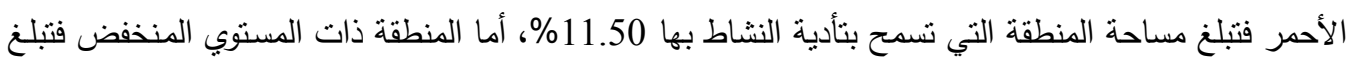
88.5 من مساحة الفراغ الكلي. 


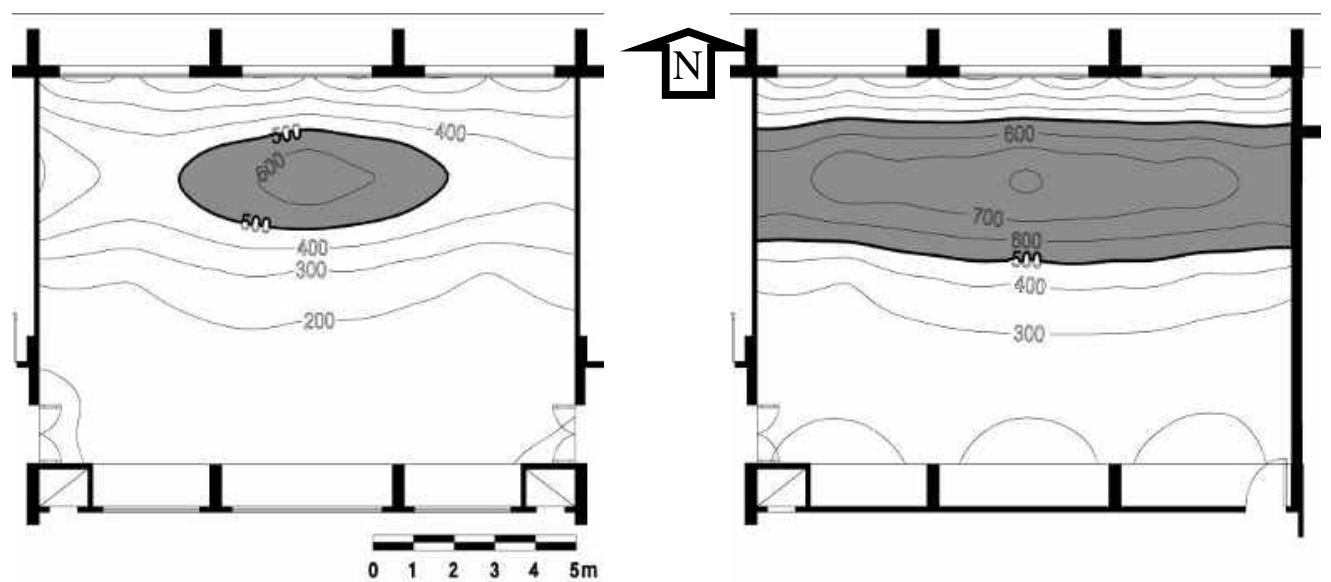

كنتور الإضاءة الطيعية في حالة الفراغ (ه) ذو الفرش أبيض كنتور الإضاءة الطييعة في حالة الفراغ (و) ذو الفرش الأحمر شكل(14): معدل انتشار الإضاءة الطبيعية بالفراغين محل القياسات

أما بالنسبة لمعدل الاختراق فيأخذ في كلا الفراغين نفس الشكل كما في شكل (15). حيث يتطابق مستوى شدة

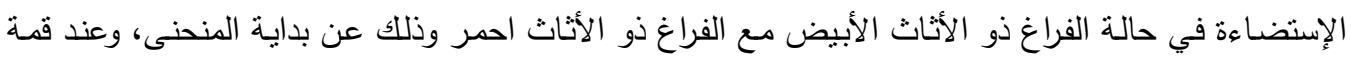

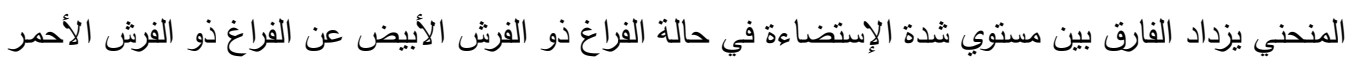

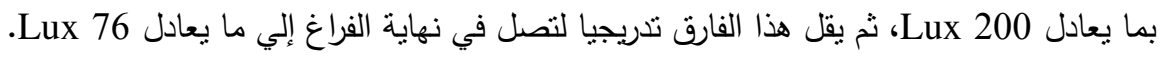

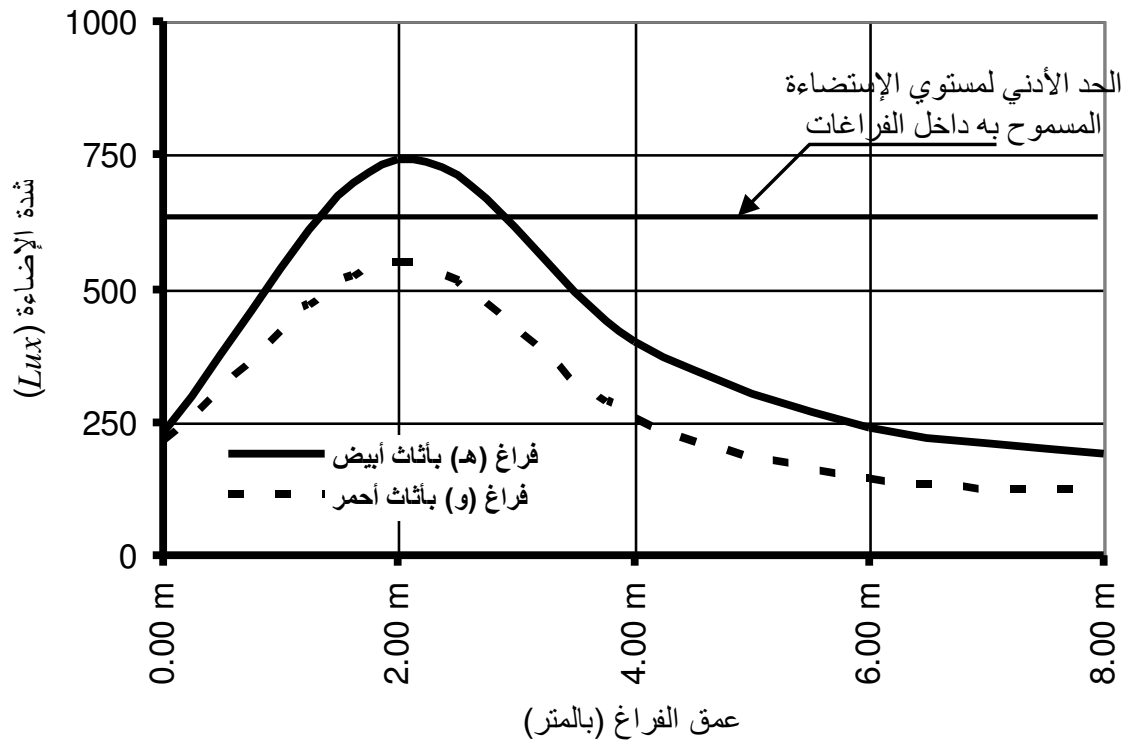

شكل(15): معدل اخترلق الإضاءة الطبيعية بالفراغين (ه)، (و) محل القياسات 


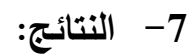

استخلاصاً من الدراسة النظرية والدراسات الميدانية أمكن الوصول إلي النقاط التالية:

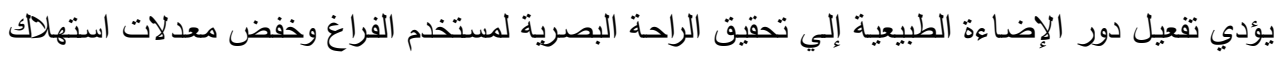

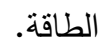

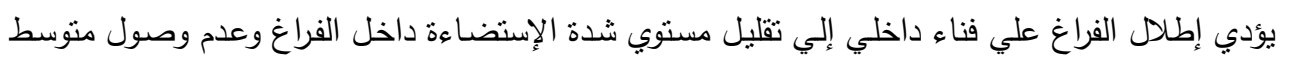

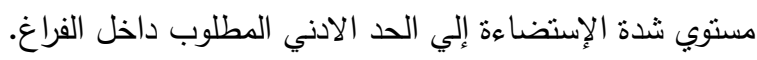

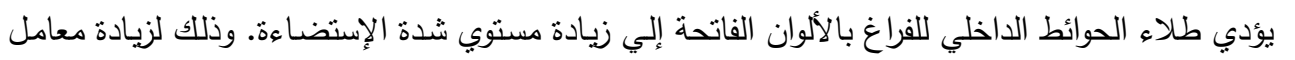

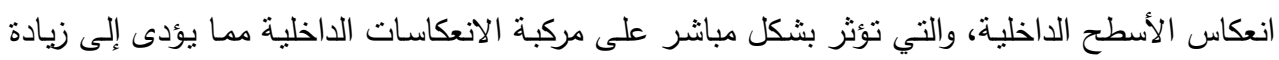
مستوى الإستضاءة بداخل الفراغ. • • ل العؤثر تغير لون الأسطح الداخلية علي معدل الاختراق للإضـاءة الطبيعية داخل الفراغ.

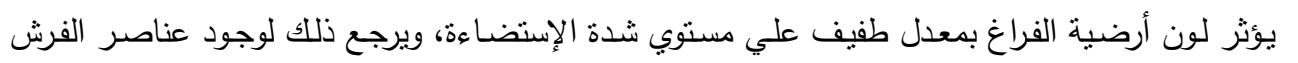

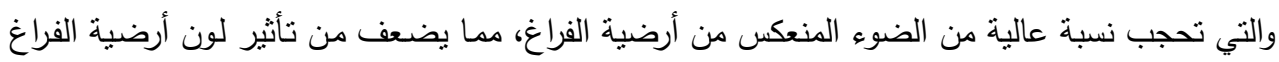
على مستوى شدة الإسنضاءة.

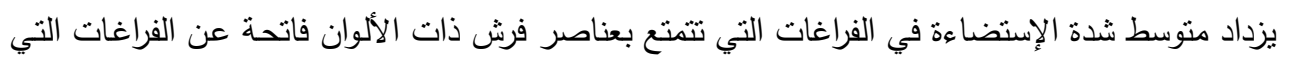

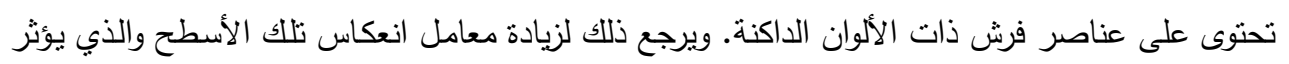

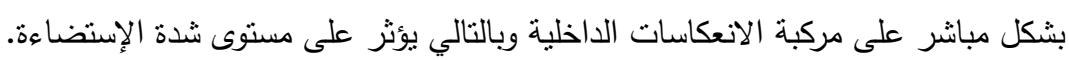

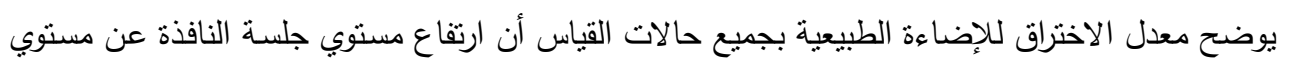
سطح العمل يؤدي إلي تقليل مسنوي شدة الإستضاءة بالمنطقة المجاورة إلي النافذة.

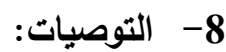

ومن خلال النتائج التي توصل البها البحث يمكن الوصول إلي مجموعة من التوصيات، وذللك للوصول إلي مباني

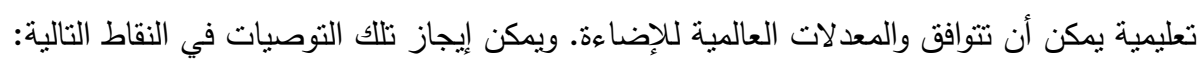

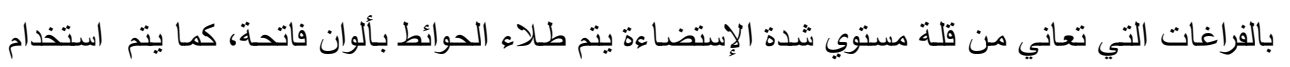
عناصر أثاث ذات الألوان الفاتحة لزيادة مركبة الانعكاسات الداخلية.

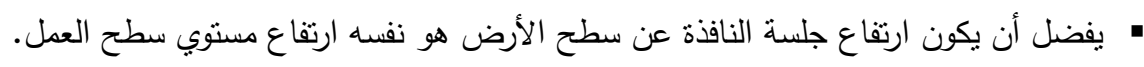

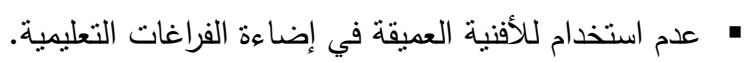

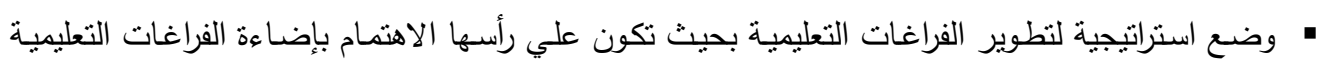
لرفع الكفاءة الوظيفية للفراغات وذلك من خلال:

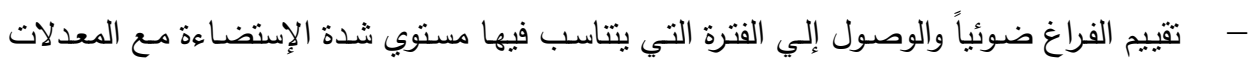
العالمية القياسية، وتكون تلاعك الفترة هي الفترة التي يقوم بها الفراغ بالمهمة التعليمية.

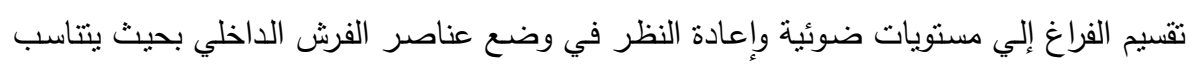
مع وظيفة الفراغ ومعدل توزيع الإضاءة داخل الفراغ. 
[1]- National fenestration Rating Council:" The facts about windows\& day lighting", January, 2005, www.nfrc.org.

[2]- Norbert Lechner:" Heating, cooling, lighting design methods for architects", A Wiley-interscienc publication, Canada, 1991,P. ( 312, 282).

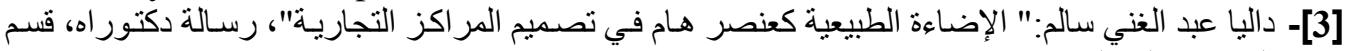

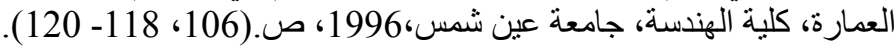

[4]- Claude L. Robbins:" day lighting design and analysis", Van Nostrand Reinhold, First edition, United States Of America, 1986, P. (3, 754- 760).

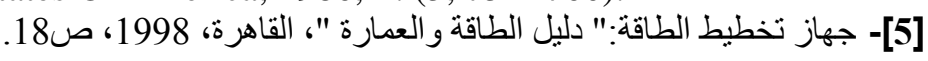

[6]- Gregg D. Ander, AIA:" day lighting performance and design", Van Nostrand Reinhold, First edition, United States Of America, 1995 , P. (2, 163 -168).

[7]- David J Cater, Faisal M Al- shareef:" A strategy for day lighting arid regions", 4th.international conference on architecture \& Urbanization, Department of architecture, Faculty of engineering, Assiut university, March, 2000, P. 5-1.

[8]- شفق العوضي الوكيل، محمد عبد الله سر اج:" المنـاخ وعمـارة المنـاطق الحـارة "، الطبعة الأولي، القاهرة،

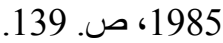

[9]- داليا عبد الغني سالم:"دراسة الإضاءة الطبيعية داخل مباني الاتريوم علي مستوي البيئة المحلية للوصول للألداء

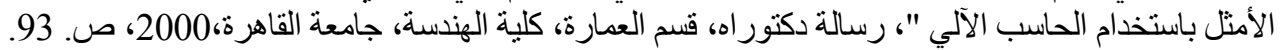

[10]- Henry J. Cowan, Peter R. Smith:" Environmental system ", Van Nostrand Reinhold Company Inc., United State Of American, 1983, P144.

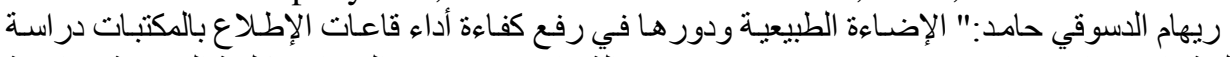

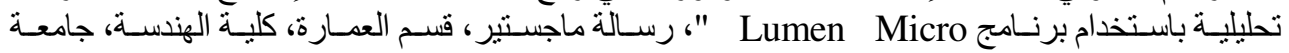

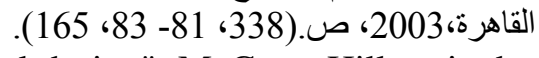

[12]- Derek Phillips:" Lighting in architectural design", McGraw-Hill, united states of America, 1964 , P. 94.

بهجت رشاد شاهين، فهي بشير:" المبني الجامعي ومو اءمته لأهداف التعليم العالي"، مكتب الاستثـارات 